Supporting Information

\title{
Mutually orthogonal bioconjugation of vinyl nucleosides for RNA metabolic labeling
}

Mrityunjay Gupta ${ }^{\dagger, \downarrow}$, Monika Singha ${ }^{\S, \hbar}$, Dnyaneshwar B. Rasale ${ }^{\S}$, Zehao Zhou ${ }^{\mathbb{I I}}$, Srijana Bhandari $^{\mathbb{I l}}$, Samantha Beasley ${ }^{\S}$, Jasmine Sakr ${ }^{\S}$, Shane M. Parker ${ }^{\mathbb{I l}, *}$, Robert C. Spitale ${ }^{\dagger, \S, *}$

†Department of Chemistry, University of California, Irvine, Irvine, CA 92697, United States

${ }^{\circledR}$ Department of Pharmaceutical Sciences, University of California, Irvine, Irvine, CA 92697, United States

IDepartment of Chemistry, Case Western Reserve University, Cleveland, OH 44106, United States 
TABLE OF CONTENTS

\begin{tabular}{|c|l|c|}
\hline Number & \multicolumn{1}{|c|}{ Title } & Page No. \\
\hline I & General Information & $2-3$ \\
\hline II & Experimental Methods & $3-13$ \\
\hline III & Supplemental Figures & $14-25$ \\
\hline IV & NMR Spectra & $26-33$ \\
\hline V & References & $33-34$ \\
\hline
\end{tabular}

\section{General Information}

All reagents were purchased from commercial suppliers and were of analytical grade and used without further purification unless otherwise noted. Reaction progress was monitored by thin-layer chromatography on EMD 60 F254 plates, visualized with UV light. Compounds were purified via flash column chromatography using Sorbent Technologies $60 \AA 230 \times 400$ mesh silica gel or Teledyne ISCO CombiFlash System with RediSep Rf Media. Preparative reverse-phase HPLC was performed on a Shimadzu LH40 equipped with a ZORBAX SB-C18 column (Agilent) with HPLC grade acetonitrile and $18 \mathrm{M} \Omega$ deionized water containing $0.1 \%$ trifluoroacetic acid. Anhydrous solvent dimethylformamide (DMF) was degassed and dried over molecular sieves. NMR spectra were acquired with Bruker NEO-400 spectrometer. All spectra were acquired at $298 \mathrm{~K}$. ${ }^{1} \mathrm{H}-\mathrm{NMR}$ spectra were acquired at $400 \mathrm{MHz},{ }^{13} \mathrm{C}-\mathrm{NMR}$ spectra were acquired at $125 \mathrm{MHz}$ and ${ }^{31} \mathrm{P}-\mathrm{NRM}$ spectra were acquired at $100 \mathrm{MHz}$. Chemical shifts are reported in ppm relative to residual non-deuterated NMR solvent unless noted otherwise and coupling 
constants $(\mathrm{J})$ are provided in $\mathrm{Hz}$. All NMR spectra was analyzed using MestreNova software. Absorbance spectra were obtained on Cary UV-Vis Spectrophotometer with $10 \mathrm{~mm}$ path length quartz cuvettes. Low and high resolution electrospray ionization (ESI) mass were collected at the University of California-Irvine Mass Spectrometry Facility.

\section{Experimental Methods}

\section{DFT Studies.}

Relaxed structures for vinyl-nucleosides (2-VA and 5-VU), maleimide and TCEP were obtained through a combination of conformational search and density functional theory (DFT) optimization. First, we generated conformers for each compound using the CREST with the GFN2-xTB semiempirical model ${ }^{1,2}$. Next, the ten lowest energy conformers according to GFN2-xTB were selected for further refinement with DFT. All density functional calculations were performed using Turbomole $7.5^{3}$. DFT optimizations were performed using the TPSS ${ }^{4,5}$ density functional including D3 ${ }^{6,7}$ dispersion corrections and def2-TZVP8 basis set (TPSS-D3/def2-TZVP). The resolution-of-the-identity $(\mathrm{RI})^{9}$ approximation was used to accelerate Coulomb two-electron integrals, and a tight integration grid $\mathrm{m} 5$ and convergence criteria (scfconv 8 , denconv $1 \mathrm{~d}-8$ ) were used. The lowest energy conformer after TPSS optimization was selected as the equilibrium structure for each compound. All DFT calculations were solvated using the conductor-like screening model $(\mathrm{COSMO})^{10}(\varepsilon=80.1)$.

The propensity to form C-P bonds between the vinyl nucleosides and TCEP was evaluated by generating relaxed potential energy surfaces as a function of the C-P bond length. Constrained optimizations were performed by fixing the distance between the beta 
carbon of the vinyl nucleoside and the phosphorus in TCEP to values from $3.6 \AA$ to $1.8 \AA$ (Figure S1).

\section{Hydrogen bonding DFT studies.}

We investigate the effect of hydrogen bonding in the stability of the intermediate complexes. We see evidence that the 2-VA/TCEP complex has intermolecular hydrogen bonding between an adenine C6NH to TCEP carbonyl with a distance of $1.99 \AA$ (Fig. 2). By contrast, in the 5-VU/TCEP complex, we find no hydrogen bond within 4.0A. That said, we expect our model to exaggerate the role of hydrogen bonding because the implicit solvation neglects hydrogen bonding with the solvent which will net destabilize the products (with artificially suppressed hydrogen bonding) relative to the complex structure. Therefore, we generated a comparison with a structure where TCEP is orientated in such a way that hydrogen bond formation is suppressed (Fig. S3). Once again, we found a stable 2-VA/TCEP intermediate but no stable 5-VU/TCEP intermediate. Finally, this behavior was verified with a different density functional (Fig. S4). Thus, we conclude that intermolecular hydrogen bonding contributes to the relative stability of the 2-VA/TCEP complex but does not explain the selectivity of the phospha-Michael reaction.

\section{NMR studies for reactivity.}

Reactivity of vinyl nucleosides was observed by dissolving the nucleotides in $\mathrm{D}_{2} \mathrm{O}$ to achieve $100 \mathrm{mM}$ concentration. 5 equivalents of maleimide/TCEP. $\mathrm{HCl}$ was added to the solution and mixed thoroughly. $400 \mu \mathrm{L}$ of this mixture was transferred to a fresh NMR tube 
and NMR spectroscopy was conducted at regular intervals, incubating the NMR tubes at room temperature between the intervals.

\section{Background reactivity studies.}

$100 \mu \mathrm{L}$ of $10 \mathrm{mM}$ Adenosine, Uridine, Guanosine and Cytidine solutions in $\mathrm{H}_{2} \mathrm{O}$ each were added into an HPLC vial. The solution was diluted with $500 \mu \mathrm{L}$ of $\mathrm{H}_{2} \mathrm{O}$ and $100 \mu \mathrm{L}$ of 50 $\mathrm{mM}$ maleimide or TCEP solution were added. The solution was then analyzed just after addition and then after incubation at room temperature for 3 hours by analytical RP-HPLC (Thermo-Scientific Hypersil BDS C18 column, $150 \times 4.6 \mathrm{~mm}, 3$ micron) at $254 \mathrm{~nm}$. Mobile phase $\mathrm{A}: \mathrm{H}_{2} \mathrm{O}+1 \%$ TFA, mobile phase $\mathrm{B}$ : $\mathrm{ACN}$. Flow rate: $0.5 \mathrm{~mL} / \mathrm{min}$. Gradient: $0-10 \%$ $\mathrm{B}$ in $4 \mathrm{~min}, 10-80 \% \mathrm{~B}$ in $3 \mathrm{~min}, 80 \% \mathrm{~B}$ for $3 \mathrm{~min}, 80-50 \% \mathrm{~B}$ in $1 \mathrm{~min}$ and $50 \% \mathrm{~B}$ for 1 minute.

\section{NMR aqueous stability data.}

Aqueous stability of 5-VU and 2-VA was assessed by dissolving the vinyl nucleotides in $\mathrm{D}_{2} \mathrm{O}$ to achieve $100 \mathrm{mM}$ final concentration. $400 \mu \mathrm{L}$ of this solution was transferred to a fresh NMR tube and NMR spectroscopy was performed at 24-hour intervals for two days, incubating the NMR tube at room temperature between the experiments.

\section{RNA biotinylation with Maleimide-biotin and TCEP-biotin.}

HEK293T cells were plated at $1 \times 10^{5}$ cells per well in a 6 -well plate and grown in Dulbecco's modified Eagle medium (DMEM, high glucose, Corning \#10-017-CM) supplemented with $10 \%$ fetal bovine serum and $1 \%$ penicillin-streptomycin $(10,000 \mathrm{U} / \mathrm{mL}$, ATCC \#30-2300) for $24-36$ hours in a $37^{\circ} \mathrm{C}, 5 \%$ carbon dioxide incubator. At the start of 
treatment, HEK293T cells were incubated in a final concentration of $1 \mathrm{mM} 5$-vinyl-uridine (Jena Bioscience \#CLK-049), 2-vinyl-adenosine or DMSO for 5 hours. The final concentration of DMSO in cell culture medium for all treatments was $0.25 \%$ DMSO for all treatments. After 5 hours, total cellular RNA was extracted with TriZol (Thermofisher \#15596026) according to the manufacturer's protocol. RNA pellets were reconstituted in nuclease-free water and quantified using a NanoDrop 2000. $15 \mu \mathrm{g}$ of each RNA sample was reacted in solutions with $1 \mathrm{mM}$ maleimide-biotin (Sigma \# B1267), 1 mM TCEP-biotin (Cayman Chemical \#25365), $1 \mathrm{mM}$ tetrazine-biotin (Sigma \#793329), or 1mM DMSO (negative controls), all of which were 10\% DMSO final reactions in nuclease-free water.

For time and concentration tests with each biotinylating reagent or DMSO (negative control), different reaction conditions were tested and compared which are specified in $\mathrm{Fi}$ S14. Reactions were performed for 3 hours or less at room temperature and with 500 RPM shaking and under dark conditions. All biotinylating reagents were all dissolved and prepared in DMSO as $10 \mathrm{mM}$ solution stocks stored in $-20^{\circ} \mathrm{C}$. RNA was purified after biotinylation using RNA Clean and Concentrator Kit \#5 (Zymo Research \#R1013) and eluted in 20 ul of nuclease-free water prior to dot blot analysis.

\section{RNA dot blot analysis with chemiluminescent imaging.}

To detected biotinylated RNA with dot blot analysis 2 ug of purified, biotinylated RNA was fixed to a Hybond-N+ (GE Healthcare) membrane with $254 \mathrm{~nm}$ light using a UV stratalinker (Stratagene). The membrane was first equilibrated in 2x SSC buffer before spotting RNA and fixing with UV-light. After fixing RNA, membranes were blocked in 
blocking buffer (0.12 M NaCl, 0.016 M Na2HPO4, 0.008 M NaH2PO4, 0.17 M SDS) for 30 minutes and followed by incubation with high sensitivity streptavidin-HRP (Fisher Scientific, Cat\#: PI21130) at 1:5000 dilution in blocking buffer for 5 minutes. The membrane was washed twice in a Wash A buffer (1:10 dilution of blocking buffer in D.I. water) for 30 minutes and twice in Wash $B$ buffer $(0.1 \mathrm{M}$ Tris-base, $0.1 \mathrm{M} \mathrm{NaCl}, 0.02 \mathrm{M}$ $\mathrm{MgCl}_{2}, \mathrm{pH}$ 9.5) for 5-10 minutes. Membranes were then incubated for 1-5 minutes in $\mathrm{ECL}$ Chemiluminescent Substrate (Fisher Scientific, Cat\#: PI32106) and imaged on a ChemiDoc MP imaging system (Bio-Rad) to detect chemiluminesence on the membrane. After imaging is completed, methylene blue $(0.04 \%$ methylene blue and $0.3 \mathrm{M}$ sodium acetate) was used to stain onto membranes over night, rinsed in D.I water, followed by colorimetric imaging with the ChemiDoc MP imaging systems to detect consistent loading of RNA onto the membranes.

\section{Cell imaging with fluorophore-conjugated reagents in HEK293T.}

HEK293T cells were grown in 6-well plates (growth conditions in section VII) onto polyD-lysine $(10 \mu \mathrm{g} / \mathrm{ml})$ coated coverslips for $24-36$ hours to ensure attachment to the coverslips. At the time of treatment, cells were incubated with $1 \mathrm{mM}$ of 5-vinyl-uridine, 2vinyl-uridine or DMSO (negative control) for 5 hours in $2 \mathrm{~mL}$ of complete DMEM per well in 6-well tissue culture plates. Cells were washed gently twice in DPBS (GenClone \# 25508 ) to remove residual complete media and subsequently fixed in $3.7 \%$ methanol-free paraformaldehyde prepared with $0.15 \%$ Triton-X100 dissolved in DPBS for 30 minutes at room temperature to ensure complete permeabilization and fixation of cells. Cells were washed twice in DPBS for 10 minutes, with gentle shaking. The following protocols 
described in the sub-sections below were used for biotinylation of fixed cellular RNA with maleimide-AlexaFluor488 or with TCEP-biotin conjugated using streptavidinAlexaFluor488. After the completion of each respective biotinylation reaction in fixed cells, DNA was stained by incubating coverslips with cells in 1:2000 Hoeschst 33342 . Then, coverslips were mounted onto slides with VectaShield Anti-fade (Vector Labs) for fluorescent confocal microscopy with a Zeiss LSM 700 microscope.

\section{Maleimide-AlexaFluor488 to image 5-vinyl-uridine labeled RNA in fixed HEK293T}

Using DMSO as a negative control, cells treated with $1 \mathrm{mM} 5$-vinyl-uridine for 5 hours are fixed with paraformaldehyde and washed in DPBS, as indicated in the procedure above. $1 \mathrm{mM}$ of unconjugated TCEP (Sigma \#75259) was prepared in DPBS to reduce disulfide bonds in which cells were incubated for 30 minutes in the dark. TCEP was removed and freshly prepared $500 \mathrm{mM}$ iodoacetamide (Sigma \# 16125) in DPBS was immediately applied to fixed cells and incubated overnight (18-20 hours) at $37^{\circ} \mathrm{C}$ in the dark carefully ensuring cells are completely immersed in solution for alkylation of endogenous thiols. These were washed with DPBS twice for 10 minutes followed by incubation in bovine serum albumin (BSA) $(1 \mathrm{mg} / \mathrm{ml}$ in DPBS) for 25 minutes, then washed again twice for 10 minutes in DPBS. Maleimide-AlexaFluor488 diluted in DPBS to $2 \mathrm{uM}$ final concertation was applied (Thermofisher \# A10254) for 30-45 minutes in the dark at room temperature, without shaking. After aspirating the maleimide solution, 3 total $0.1 \%$ Triton-X100 in DPBS washes were done for 5 minutes each with gentle shaking. Hoechst 33342 (Thermofisher $\# \mathrm{H} 3570)$ diluted in DPBS 1:2000 was incubated at room temperature in the dark for 10- 
20 minutes and washes with DPBS 3 times for 5 minutes. Coverslips were mounted onto slides for imaging.

TCEP-biotin conjugated with streptavidin-AlexaFluor488 to image 2-vinyl-adenosine labeled RNA in fixed HEK293T

Using DMSO as a negative control, cells treated with 2-vinyl-adenosine are fixed with paraformaldehyde and washed in DPBS, identical to the protocols above. To block endogenous biotin-containing proteins, $2 \mathrm{mg} / \mathrm{ml}$ unconjugated streptavidin (Thermofisher \# 21125) was dissolved in DPBS and incubated with fixed cells for 30 minutes. Without aspirating, BSA was added ( $1 \mathrm{mg} / \mathrm{ml}$ in DPBS) for 35 minutes and then washed again twice for 10 minutes in DPBS with gentle shaking. After aspirating DPBS, $100 \mu \mathrm{M}$ of TCEP-biotin was prepared in nuclease-free water and incubated on cells for 30 minutes in dark conditions without shaking, at room temperature. After washing in DPBS for 10 minutes, twice, $2 \mathrm{mg} / \mathrm{ml}$ of streptavidin-AlexaFluor488 (Thermofisher \#S11223) was dissolved 1:1000 in DPBS and applied to cells for 30 minutes in order to conjugate the fluorophore onto biotinylated, labeled RNA. After aspirating, 0.1\% Triton-X100 in DPBS washes were done for 5 minutes. Hoechst 33342 (Thermofisher \#H3570) diluted in DPBS 1:2000 was incubated at room temperature in the dark for 10-20 minutes and washes with DPBS 3 times for 5 minutes. Coverslips were mounted onto slides for imaging. 


\section{Synthesis of 5-vinyl-uridine (5-VU).}<smiles>C=Cc1cn(C2OC(CO)C(O)C(O)C2O)c(=O)[nH]c1=O</smiles>

5-vinyl-uridine was prepared according to previously reported method. ${ }^{12}$ Briefly, 5lodouridine $\left(0.50 \mathrm{~g}, 1.35 \mathrm{mmol}, \mathrm{Pd}_{2}(\mathrm{dba})_{3}(67.5 \mathrm{mg}, 67.6 \mu \mathrm{mol}), \mathrm{AsPh}_{3}(82.7 \mathrm{mg}, 0.27\right.$ mmol) was dissolved in anhydrous DMF and purged with $\mathrm{N}_{2}$ for 15 minutes $(3 \mathrm{~mL})$. Tributylvinylstannane $(0.47 \mathrm{~mL}, 1.62 \mathrm{mmol})$ was added to the mixture and stirred with heating in an oil bath for $10 \mathrm{~h}$ at $80^{\circ} \mathrm{C}$. Upon completion, the mixture was concentrated in vacuo and purified by column chromatography (EtOAc followed by $0-10 \% \mathrm{MeOH} / \mathrm{DCM}$ ) to give $5-\mathrm{VU}(0.25 \mathrm{mg}, 69 \%)$ as a white solid. ${ }^{1} \mathrm{H}$ NMR (400 MHz, DMSO) $\delta 11.43(\mathrm{~s}, 1 \mathrm{H})$, $8.20(\mathrm{~s}, 1 \mathrm{H}), 6.37$ (dd, $J=17.7,11.6 \mathrm{~Hz}, 1 \mathrm{H}), 5.91(\mathrm{dd}, J=17.7,2.0 \mathrm{~Hz}, 1 \mathrm{H}), 5.78(\mathrm{~d}, J$ $=4.7 \mathrm{~Hz}, 1 \mathrm{H}), 5.41(\mathrm{~d}, J=5.5 \mathrm{~Hz}, 1 \mathrm{H}), 5.23(\mathrm{t}, J=4.9 \mathrm{~Hz}, 1 \mathrm{H}), 5.12(\mathrm{dd}, J=11.5,1.9 \mathrm{~Hz}$, 1H), $5.06(\mathrm{~d}, J=5.4 \mathrm{~Hz}, 1 \mathrm{H}$ ), 4.03 (ddd, $J=24.8,10.0,5.0 \mathrm{~Hz}, 2 \mathrm{H}$ ), 3.86 (dd, $J=7.4,2.8$ $\mathrm{Hz}, 1 \mathrm{H}), 3.73-3.66(\mathrm{~m}, 1 \mathrm{H}), 3.62-3.54(\mathrm{~m}, 1 \mathrm{H}) .{ }^{13} \mathrm{C}$ NMR $(126 \mathrm{~Hz}$, DMSO) $\delta 162.1$ $149.8,138.0,128.6,114.0,110.8,88.2,84.6,73.9,69.4,60.4$.

Synthesis of 2-vinyl-adenosine (2-VA).<smiles>C=Cc1nc(N)c2ncn(C3OC4C(O)C(CO)OC43)c2n1</smiles> 
2-vinyl-adenosine was synthesized according to previously reported method. ${ }^{12}$ Briefly, 2lodoadenosine (500 mg, $1.27 \mathrm{mmol}), \mathrm{Pd}_{2} \mathrm{dba}_{3}(58.2 \mathrm{mg}, 63.5 \mu \mathrm{mol})$, and $\mathrm{AsPh}_{3}(77.9 \mathrm{mg}$, $0.25 \mathrm{mmol}$ ) was dissolved in DMF $(1.3 \mathrm{~mL})$ and stirred with heating in an oil bath at 80 ${ }^{\circ} \mathrm{C}$. Tributylvinylstannane $(0.45 \mathrm{~mL}, 1.53 \mathrm{mmol})$ was added to the mixture and stirred for $10 \mathrm{~h}$. The reaction was then concentrated in vacuo and purified by silica flash column chromatography (10\% MeOH/DCM) to give 2-VA (335 mg, 90\%) as a tan solid. ${ }^{1} \mathrm{H}$ NMR (400 MHz, DMSO) $\delta 8.32$ (s, 1H), 7.30 (s, 2H), 6.60 (dd, J = 17.3, $10.4 \mathrm{~Hz}, 1 \mathrm{H}), 6.36$ (dd, $J=17.3,2.3 \mathrm{~Hz}, 1 \mathrm{H}), 5.88(\mathrm{~d}, J=6.5 \mathrm{~Hz}, 1 \mathrm{H}), 5.55(\mathrm{dd}, J=10.4,2.3 \mathrm{~Hz}, 1 \mathrm{H}), 5.46-5.28$ (m, 1H), $5.19(\mathrm{~d}, J=4.4 \mathrm{~Hz}, 1 \mathrm{H}), 4.65(\mathrm{dd}, J=11.2,6.0 \mathrm{~Hz}, 1 \mathrm{H}), 4.15(\mathrm{dd}, J=7.2,4.5$ $\mathrm{Hz}, 1 \mathrm{H}), 3.97(\mathrm{dd}, J=6.3,3.4 \mathrm{~Hz}, 1 \mathrm{H}), 3.68(\mathrm{dt}, J=12.0,4.2 \mathrm{~Hz}, 1 \mathrm{H}), 3.61-3.49(\mathrm{~m}$, 1H). ${ }^{13} \mathrm{C}$ NMR (126 MHz, DMSO) $\delta 157.8,155.8,149.7,140.4,137.1,121.2,118.6,87.7$, $86.0,73.3,70.8,61.8$.

Synthesis of 1-((2R,3R,4S,5R)-3,4-dihydroxy-5-(hydroxymethyl)tetrahydrofuran-2yl)-6,6a,9a,9b-tetrahydro-1H-pyrrolo[3,4-h]quinazoline-2,4,7,9(3H,8H)-tetraone (1).

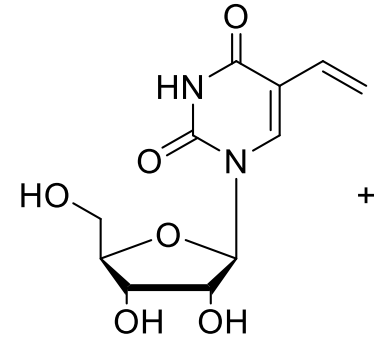

5-VU

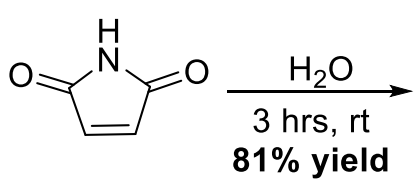
$\mathrm{HO}$

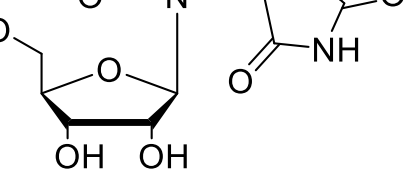

1

Maleimide (7.2 $\mathrm{mg}, 0.074 \mathrm{mmol})$ was added to a solution of $5-\mathrm{VU}(10 \mathrm{mg}, 0.037 \mathrm{mmol})$ in $\mathrm{H}_{2} \mathrm{O}(1 \mathrm{~mL})$ in a $1.5 \mathrm{~mL}$ eppendorf tube at room temperature. The resulting solution was incubated in a shaker at room temperature. After 3 hours, 
2,3-dimethyl-1,3-butadiene ( $84 \mu \mathrm{L}, 0.74 \mathrm{mmol})$ was added in the eppendorf tube and incubated in a shaker for 1 hour. The resulting solution was washed with chloroform (300 $\mu \mathrm{L} \times 3$ ) to remove the organic impurities and aqueous layer was dried in vacuo to obtain compound 1 (11 mg, 81\%) as white solid. Extinction coefficient $\varepsilon$ (220 nm, absorbance maxima $)=10670.2 \pm 612.5 \mathrm{M}^{-1} \mathrm{~cm}^{-1}, \varepsilon(260 \mathrm{~nm})=2081.3 \pm 201.2 \mathrm{M}^{-1} \mathrm{~cm}^{-1}$. HRMS Calcd for $\mathrm{C}_{15} \mathrm{H}_{17} \mathrm{~N}_{3} \mathrm{O} 8 \mathrm{Na}\left[\mathrm{M}+\mathrm{Na}^{+}\right]$390.0913, found $390.0928\left[\mathrm{M}+\mathrm{Na}^{+}\right] .{ }^{1} \mathrm{H}$ NMR $(400 \mathrm{MHz}$, DMSO) $\delta 11.14(\mathrm{~s}, 1 \mathrm{H}), 10.43(\mathrm{~s}, 1 \mathrm{H}), 7.02(\mathrm{~s}, 1 \mathrm{H}), 5.58(\mathrm{~d}, J=5.5 \mathrm{~Hz}, 1 \mathrm{H}), 5.06(\mathrm{~d}, J=$ $5.5 \mathrm{~Hz}, 1 \mathrm{H}), 4.90(\mathrm{~d}, J=5.4 \mathrm{~Hz}, 1 \mathrm{H}), 4.82(\mathrm{t}, J=5.1 \mathrm{~Hz}, 1 \mathrm{H}), 4.43-4.39(\mathrm{~m}, 1 \mathrm{H}), 4.29$ (q, $J=5.5 \mathrm{~Hz}, 1 \mathrm{H}$ ), $3.98(\mathrm{dd}, J=10.1,5.2 \mathrm{~Hz}, 1 \mathrm{H}), 3.90(\mathrm{dd}, J=8.6,5.1 \mathrm{~Hz}, 1 \mathrm{H}), 3.72$ (dd, $J=7.8,4.0 \mathrm{~Hz}, 1 \mathrm{H}$ ), $3.58(\mathrm{ddd}, J=11.6,5.0,3.5 \mathrm{~Hz}, 1 \mathrm{H}), 3.53-3.48(\mathrm{~m}, 1 \mathrm{H}), 3.14$ (t, $J=8.4 \mathrm{~Hz}, 1 \mathrm{H}), 2.72(\mathrm{dd}, J=15.0,7.9 \mathrm{~Hz}, 1 \mathrm{H}), 2.33(\mathrm{~s}, 1 \mathrm{H}) \cdot{ }^{13} \mathrm{C}$ NMR $(101 \mathrm{MHz}$, DMSO) $\delta 180.1,178.0,160.0,151.6,136.2,128.8,90.7,83.7,70.5,69.7,61.4,50.9$, $45.5,25.2$.

Synthesis of 3-((2-(6-amino-9-((2R,3R,4S,5R)-3,4-dihydroxy-5-

(hydroxymethyl)tetrahydrofuran-2-yl)-9H-purin-2-yl)ethyl)bis(2carboxyethyl)phosphonio)propanoate (2).

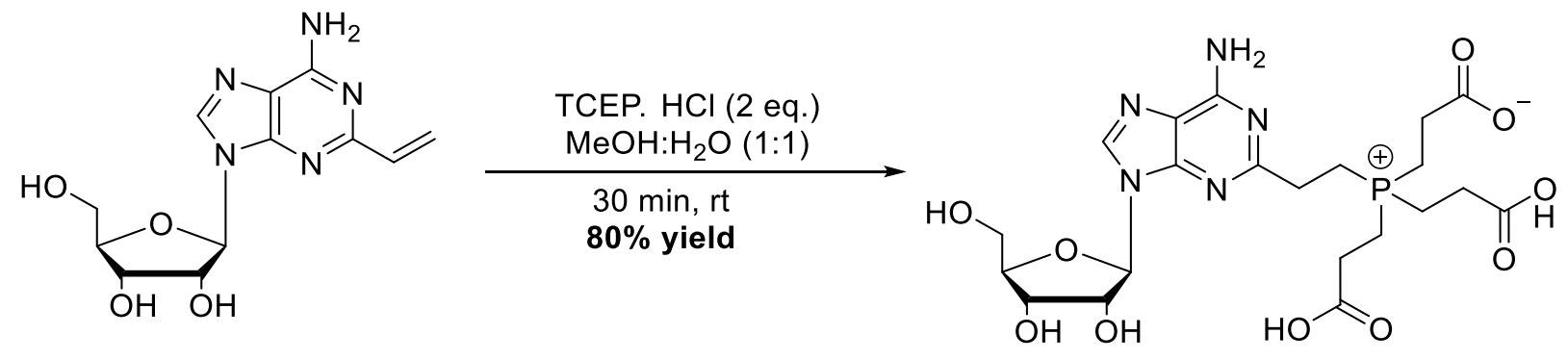


TCEP. $\mathrm{HCl}(19.5 \mathrm{mg}, 0.068 \mathrm{mmol})$ was added to a solution of 2-VA $(10 \mathrm{mg}, 0.034 \mathrm{mmol})$ in $\mathrm{MeOH} / \mathrm{H}_{2} \mathrm{O}(1 \mathrm{~mL}, 1: 1)$ at room temperature. The resulting solution was stirred at room temperature for 30 minutes. The reaction mixture was evaporated to dryness in vacuo and then purified by semi-preparative RP-HPLC (Thermo-Scientific Hypersil BDS C18 column, $150 \times 4.6 \mathrm{~mm}, 3$ micron) at $254 \mathrm{~nm}$ to obtain compound $2(15 \mathrm{mg}, 80 \%)$ as a white solid. Mobile phase $A: \mathrm{H}_{2} \mathrm{O}+1 \%$ TFA, mobile phase $\mathrm{B}$ : ACN. Flow rate: $3 \mathrm{~mL} / \mathrm{min}$. Gradient: $0-10 \%$ B in 20 min and $10-100 \%$ B in 15 min. HRMS Calcd for $\mathrm{C}_{21} \mathrm{H}_{30} \mathrm{~N}_{5} \mathrm{O}_{10} \mathrm{PH}$ $\left[\mathrm{M}+\mathrm{H}^{+}\right] 544.1808$, found $544.1809\left[\mathrm{M}+\mathrm{H}^{+}\right]$. Extinction coefficient $\varepsilon(210 \mathrm{~nm}$, absorbance $\operatorname{maxima})=12063.0 \pm 457.5 \mathrm{M}^{-1} \mathrm{~cm}^{-1}, \varepsilon(260 \mathrm{~nm})=8353.4 \pm 278.6 \mathrm{M}^{-1} \mathrm{~cm}^{-1} .{ }^{1} \mathrm{H}$ NMR $(400$ $\left.\mathrm{MHz}, \mathrm{D}_{2} \mathrm{O}\right) \delta 8.50(\mathrm{~s}, 1 \mathrm{H}), 6.13(\mathrm{~d}, J=5.2 \mathrm{~Hz}, 1 \mathrm{H}), 4.41(\mathrm{t}, J=4.8 \mathrm{~Hz}, 1 \mathrm{H}), 4.22(\mathrm{dd}, J=$ 7.6, $4.2 \mathrm{~Hz}, 1 \mathrm{H}$ ), 3.87 (dd, $J=12.7,3.1 \mathrm{~Hz}, 1 \mathrm{H}), 3.79(\mathrm{dd}, J=12.7,4.4 \mathrm{~Hz}, 1 \mathrm{H}), 3.37$ (dt, $J=10.8,7.9 \mathrm{~Hz}, 2 \mathrm{H}), 2.99(\mathrm{dt}, J=12.3,4.5 \mathrm{~Hz}, 2 \mathrm{H}), 2.83(\mathrm{dt}, J=7.3,6.3 \mathrm{~Hz}, 8 \mathrm{H}), 2.71$ (dt, $J=14.9,7.5 \mathrm{~Hz}, 8 \mathrm{H}) .{ }^{13} \mathrm{C} N M R\left(125 \mathrm{~Hz}, \mathrm{D}_{2} \mathrm{O}\right) 174.4,174.3,163.0,162.7,154.9,154.7$, $150.5,148.5,142.8,120.6,117.7,117.6,114.8,88.3,85.4,74.2,70.2,61.0,26.0,25.7$ $25.7,15.8,15.3,14.5,14.1,14.0$. 


\section{Supplemental Figures}

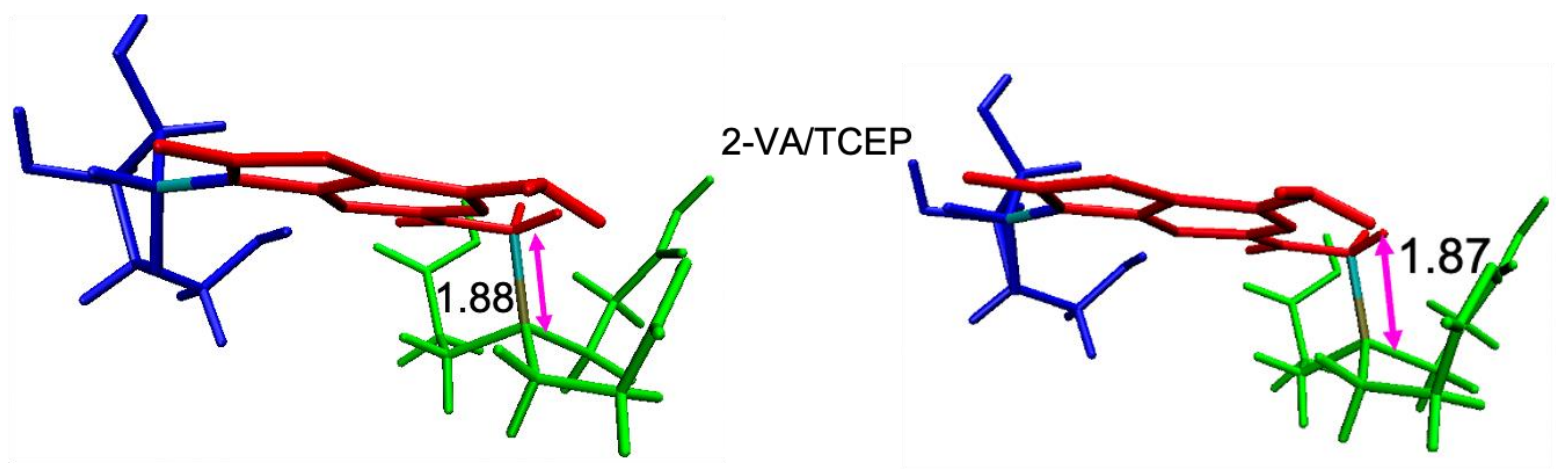

Initial

Final

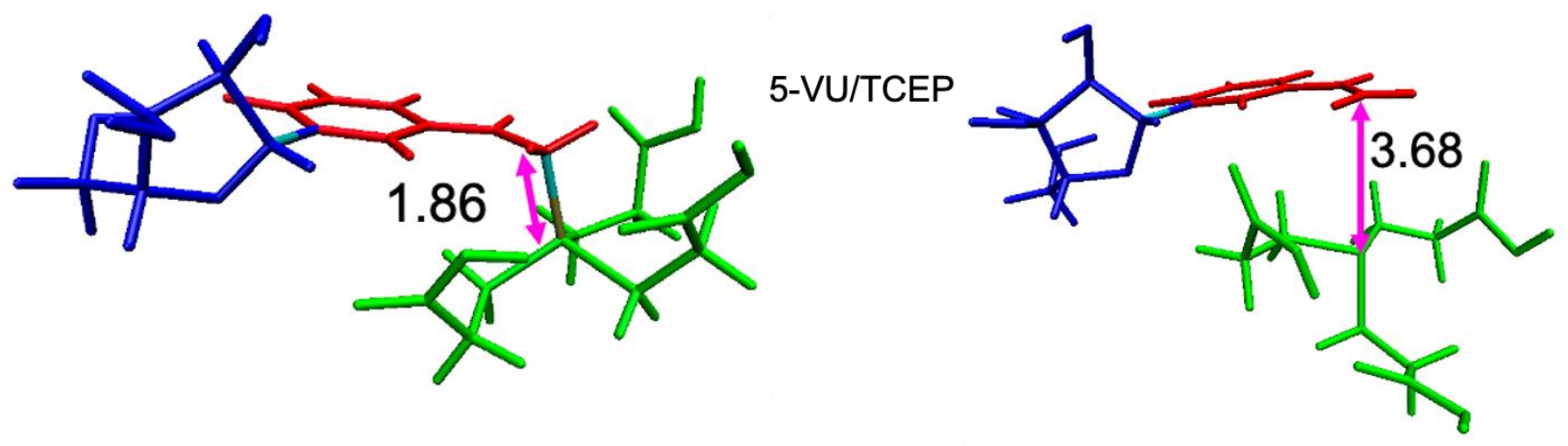

Figure S1. Illustration of bond C-P bond breaking in 5-VU/TCEP intermediate complex during optimization indicated by a longer C-P bond length in lower right panel (3.68 $\AA$ ). 


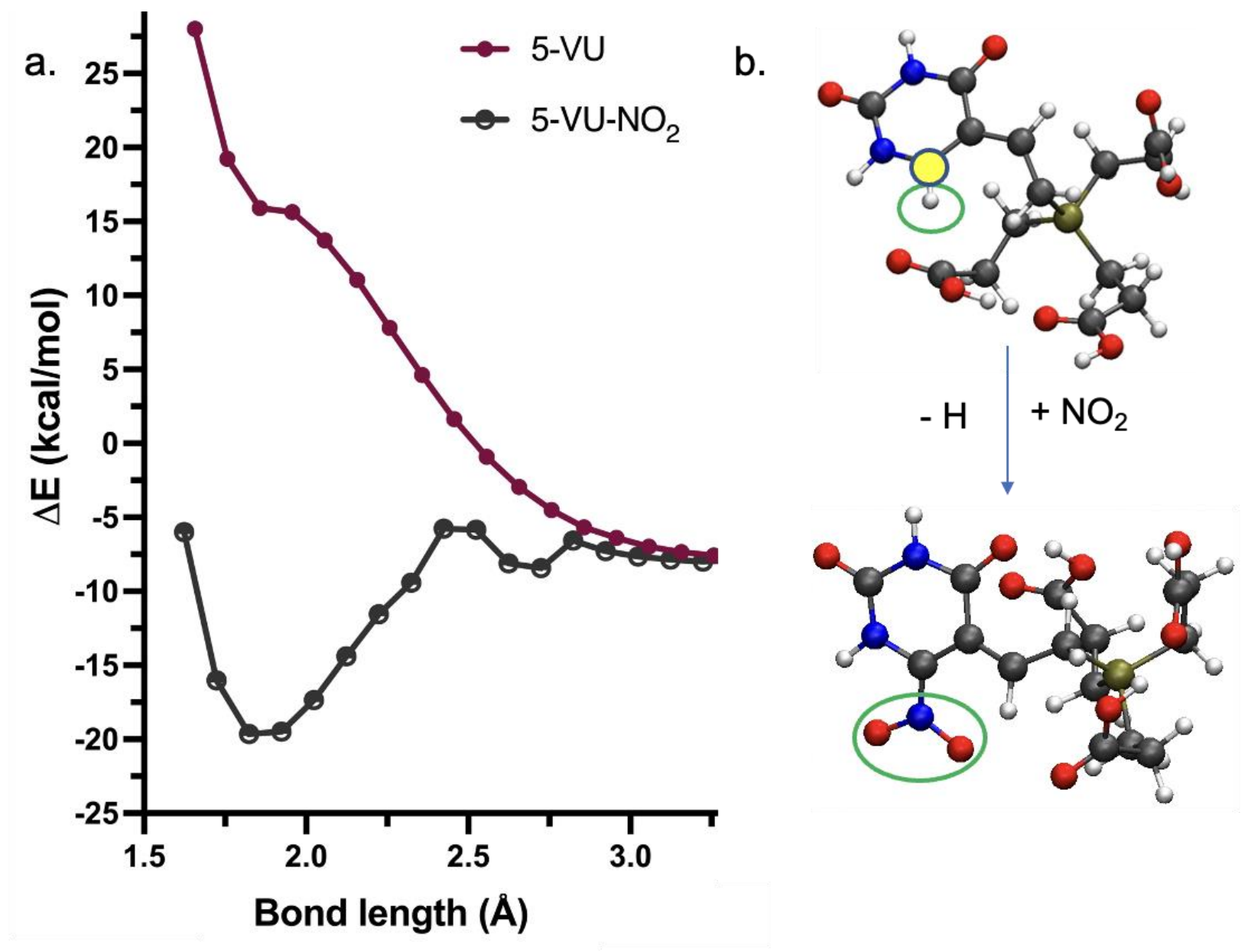

Figure S2. Stabilization of the 5-VU intermediate complex indicated by shallower potential energy surface when $\mathrm{H}$ of $\mathrm{C}-6$ of uracil (highlighted yellow) is substituted by an electron withdrawing -NO2 group. The potential energy surface of 5-VU is duplicated for easy comparison. b. Schematic of 5-VU and 5-VU- $\mathrm{NO}_{2}$ molecular structures. 

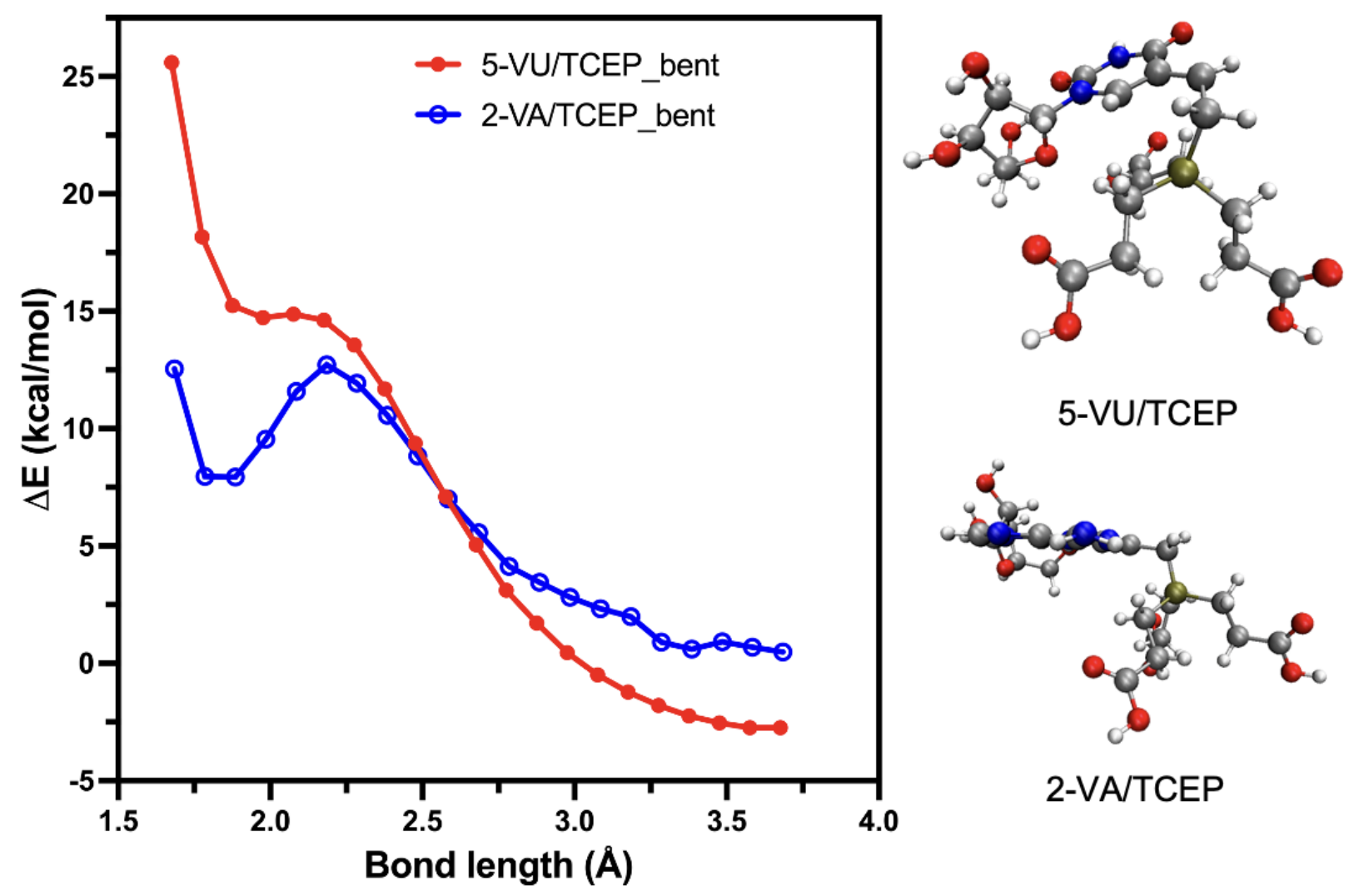

Figure S3. Potential energy scan where TCEP is kept spatially away from the nucleoside.
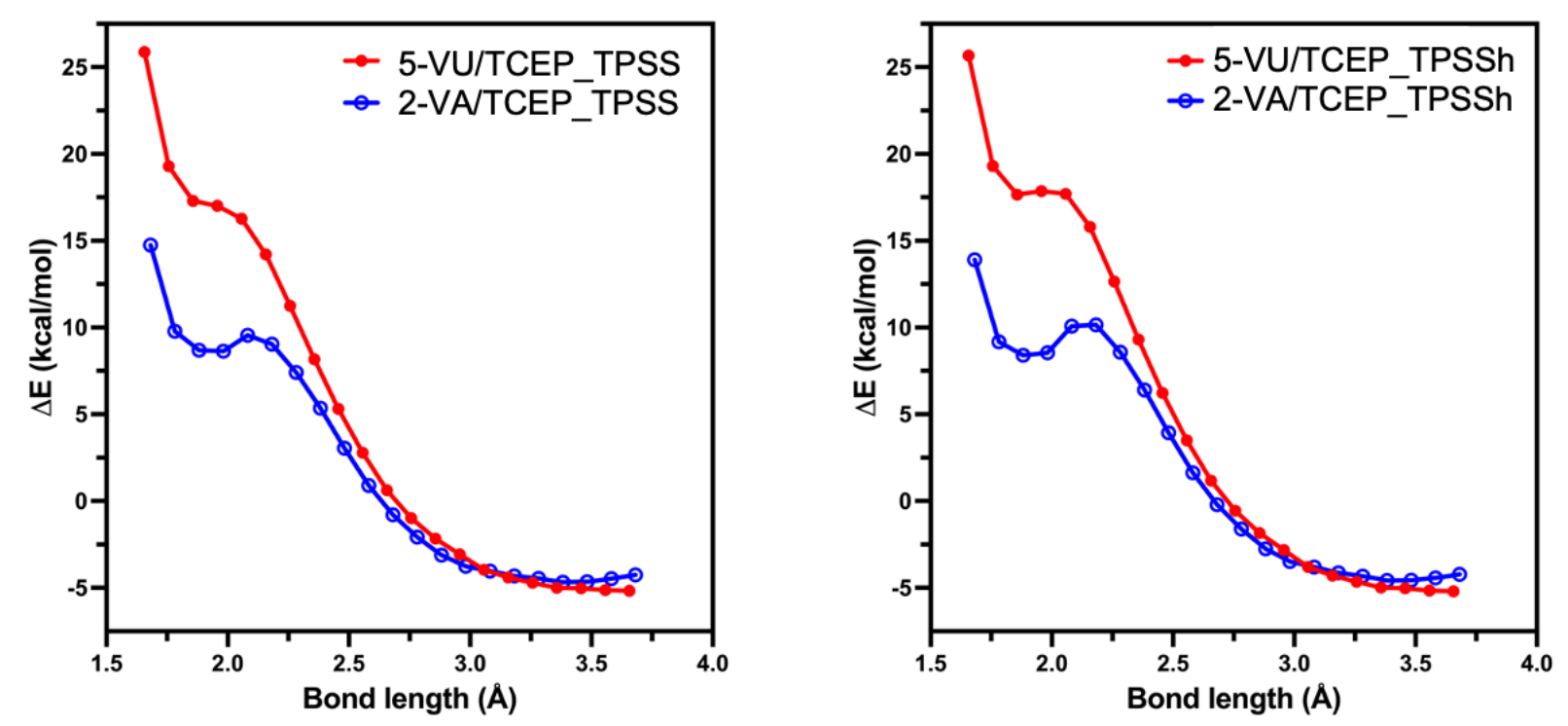

Figure S4. Potential energy scan with TPSSh functional (right panel). The scan with TPSS (left panel) is duplicated for easy comparison. 


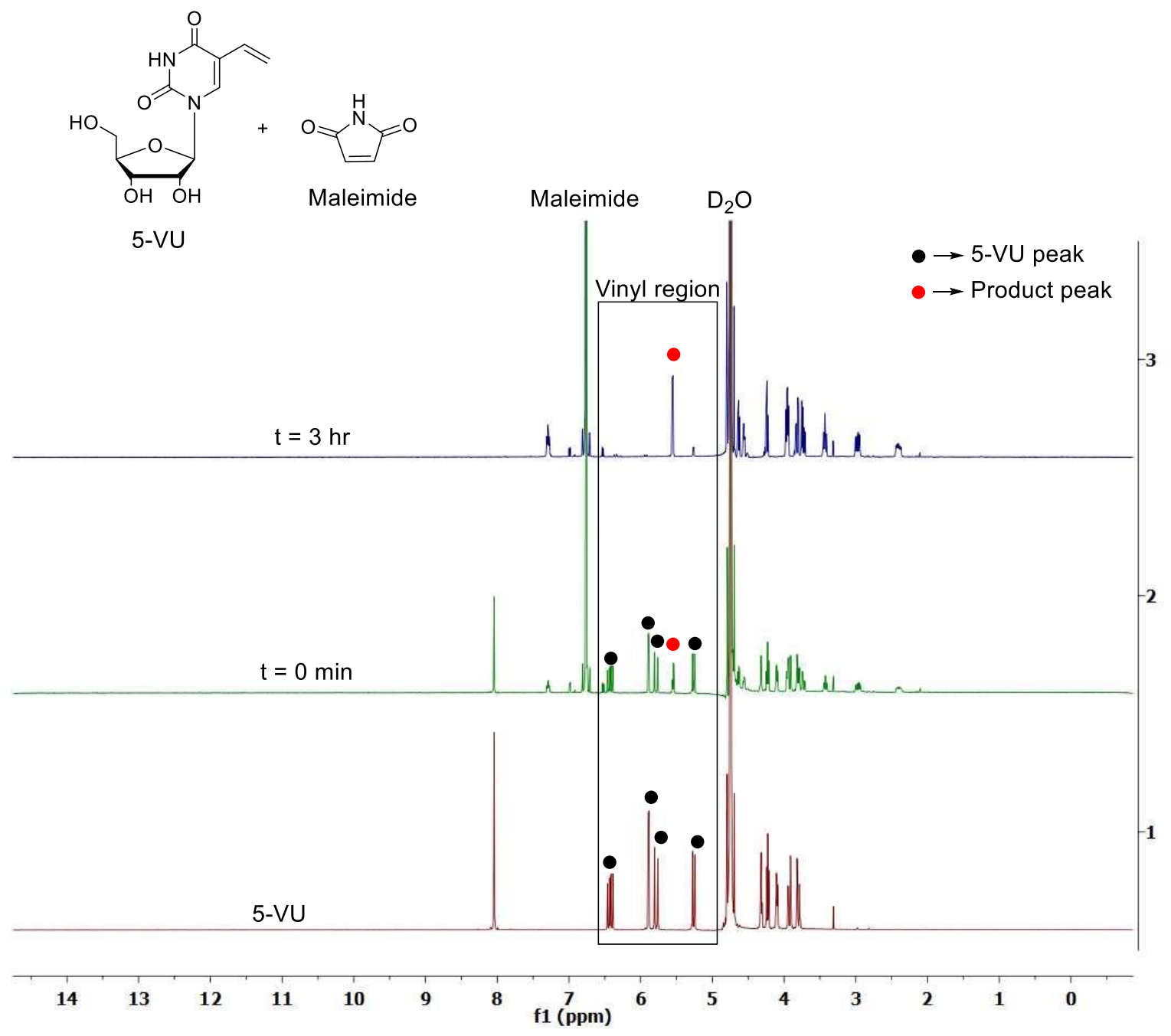

Figure S5. Reactivity study of 5-VU with maleimide. Characteristic vinyl peaks of 5-VU were observed to disappear after 3-hour incubation at room temperature. 

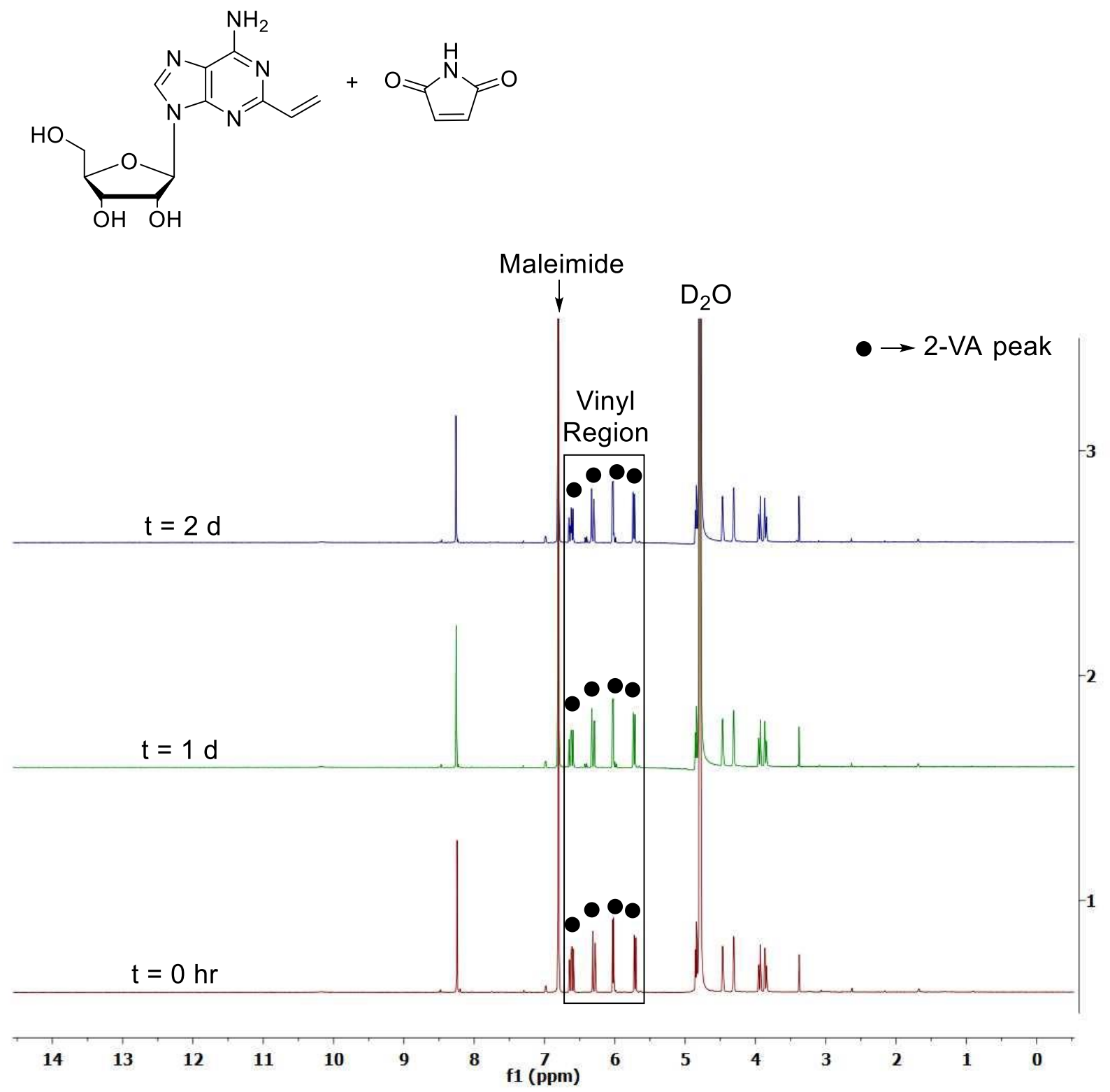

Figure S6. Reactivity study of 2-VA with maleimide. Characteristic vinyl peaks of 2-VA and other peaks were observed to remain intact after 48-hour incubation at room temperature. 
<smiles>C=Cc1cn(C2OC(O)C(CO)OC2O)c(=O)[nH]c1=O</smiles>

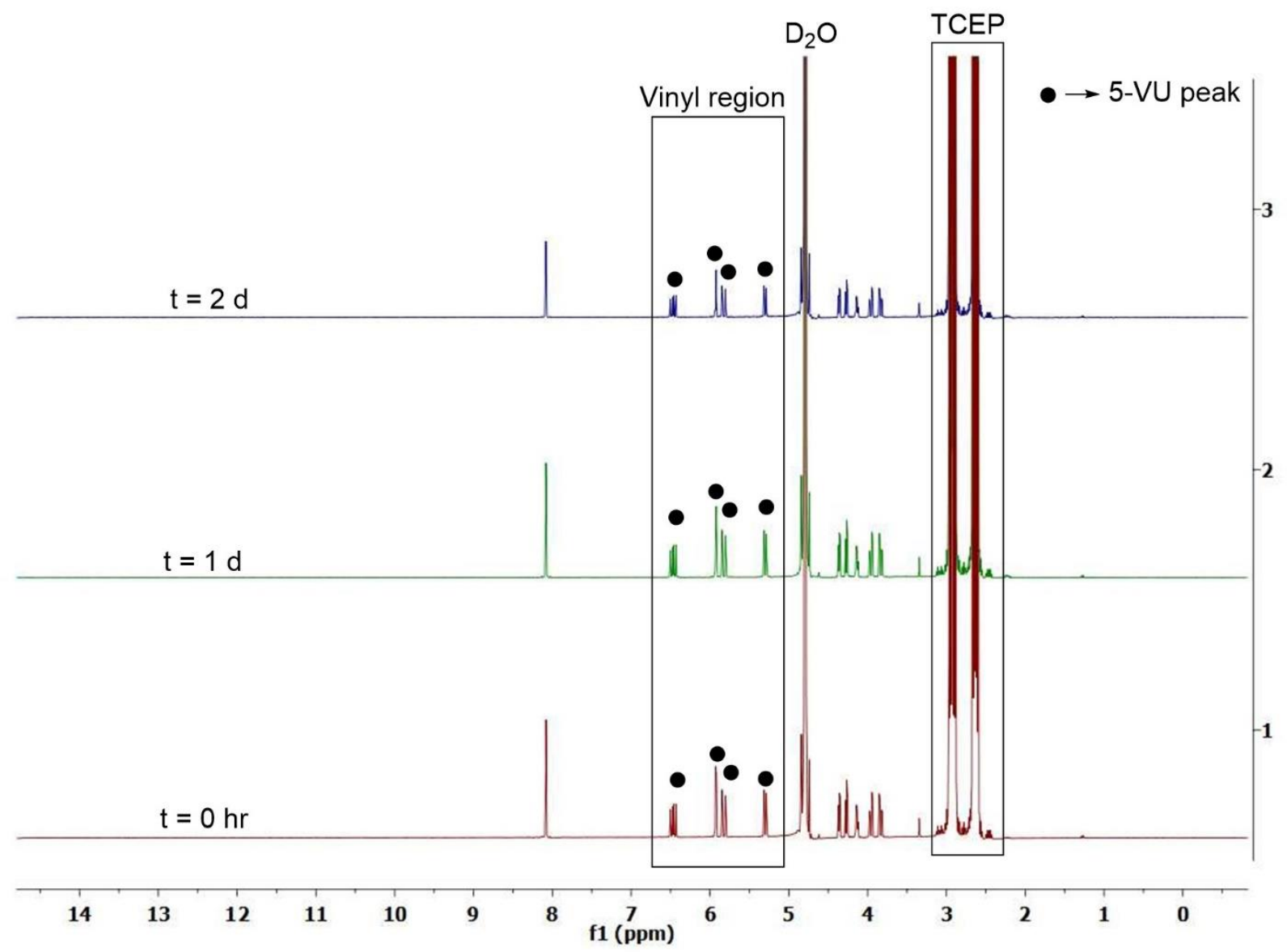

Figure S7. Reactivity study of 5-VU with TCEP.HCl. Characteristic vinyl peaks of 5-VU and other peaks were observed to remain intact after 48-hour incubation at room temperature. 


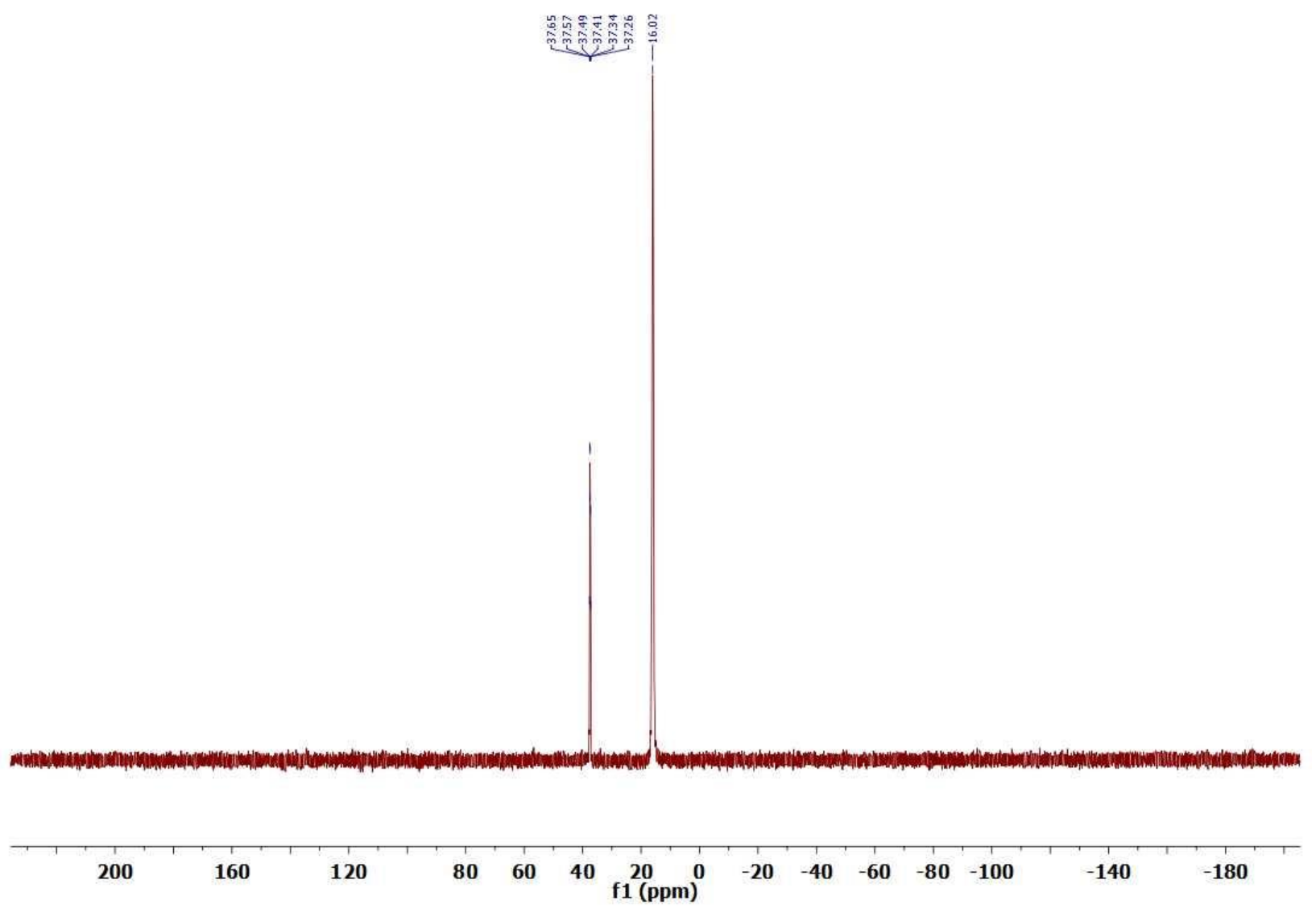

Figure S8. Reactivity study of 2-VA with TCEP by ${ }^{31} \mathrm{P}$ NMR. An upfield peak for product appears at $37.45 \mathrm{ppm}$. Chemical shift calibrated with residual TCEP at $16.02 \mathrm{ppm}$. 
<smiles>C=Cc1nc(N)c2ncn(C3OCC(O)C(O)O3)c2n1</smiles><smiles>O=C(O)CCP(CCC(=O)O)CCC(=O)O</smiles>

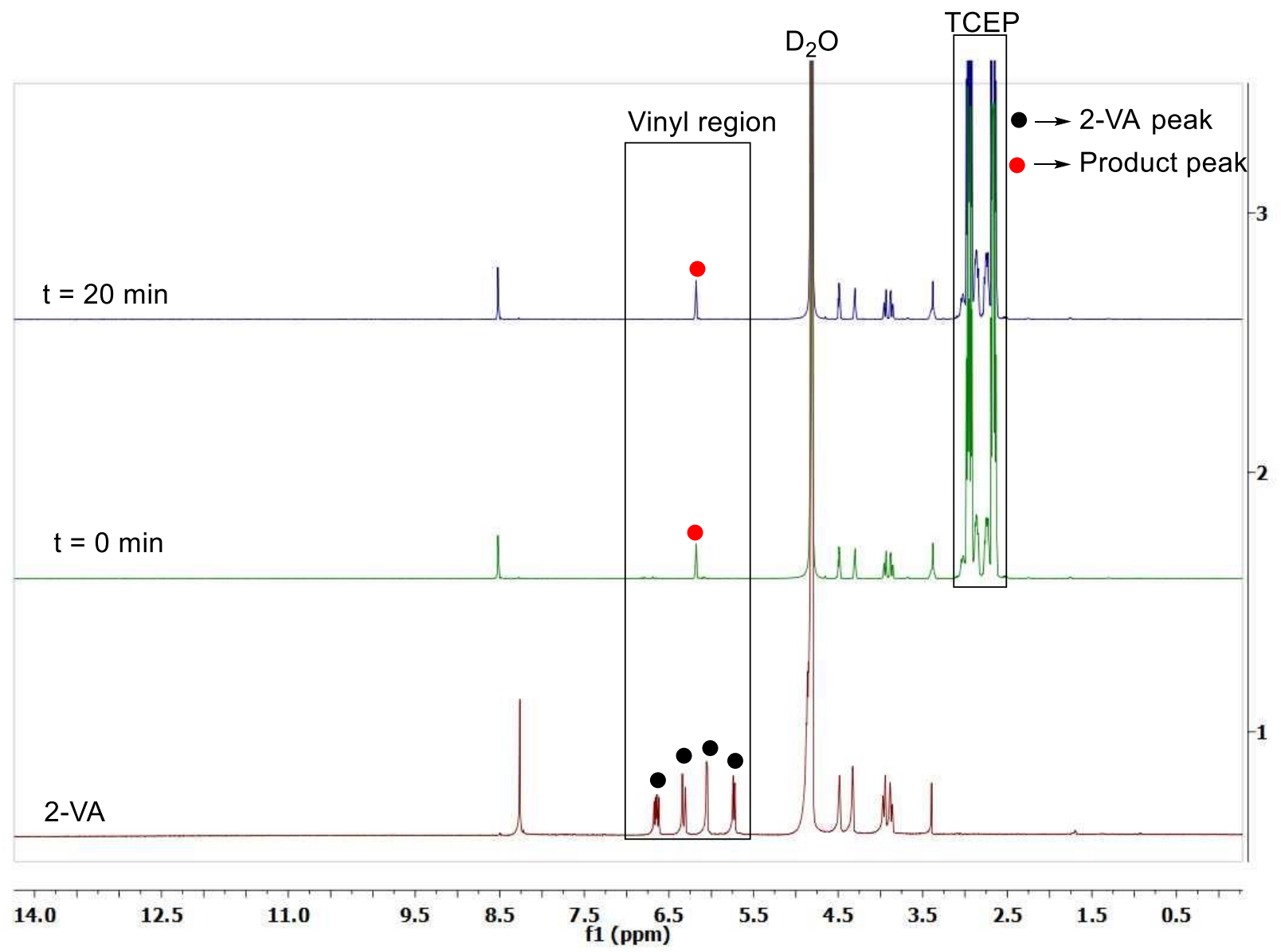

Figure S9. Reactivity study of 2-VA with TCEP.HCl. Characteristic vinyl peaks of 2-VA were observed to completely disappear after 20 minutes incubation at room temperature. 


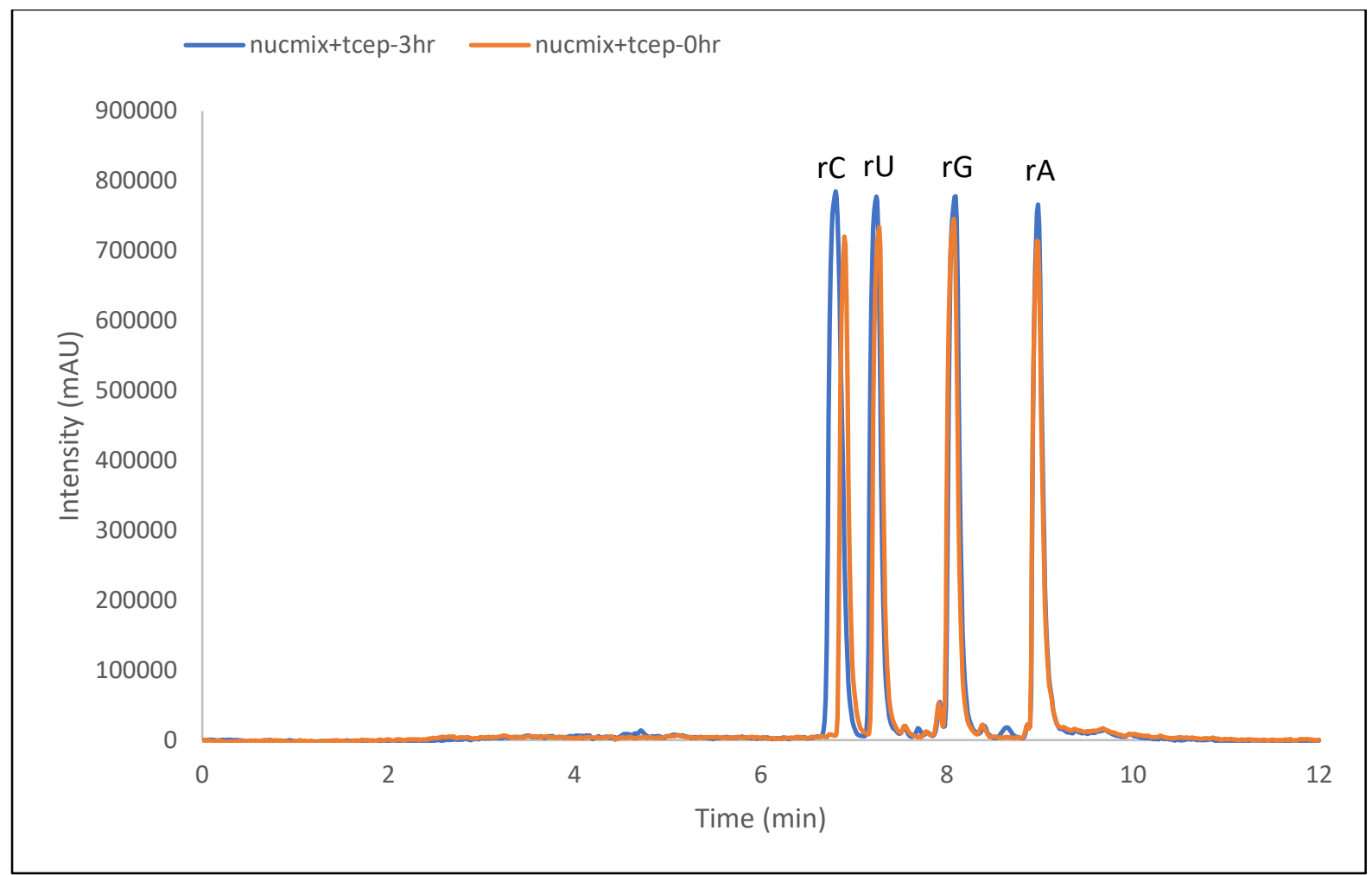

Figure S10. Background reactivity study of natural ribonucleosides incubated with TCEP.

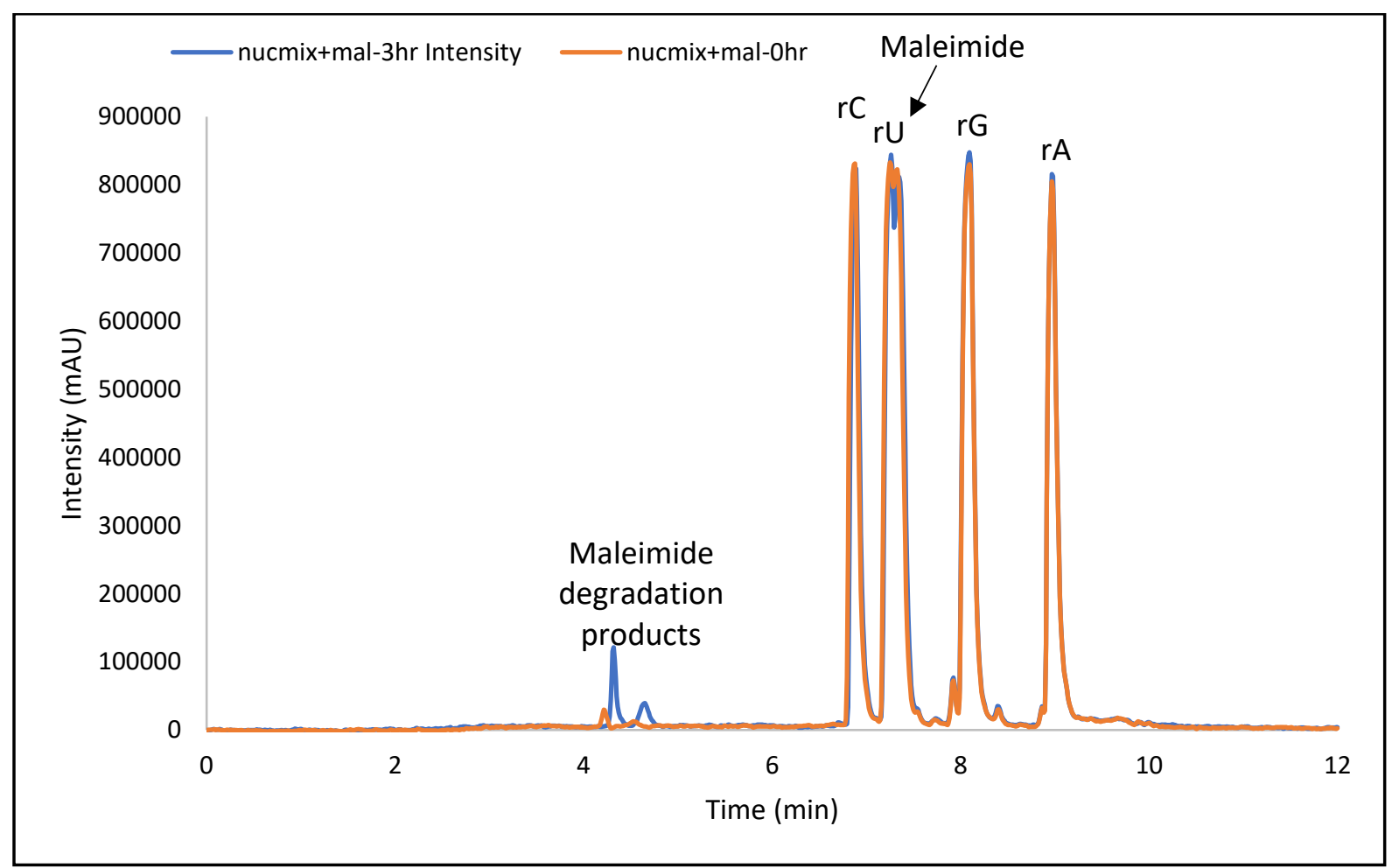

Figure S11. Background reactivity study of natural ribonucleosides incubated with maleimide. 


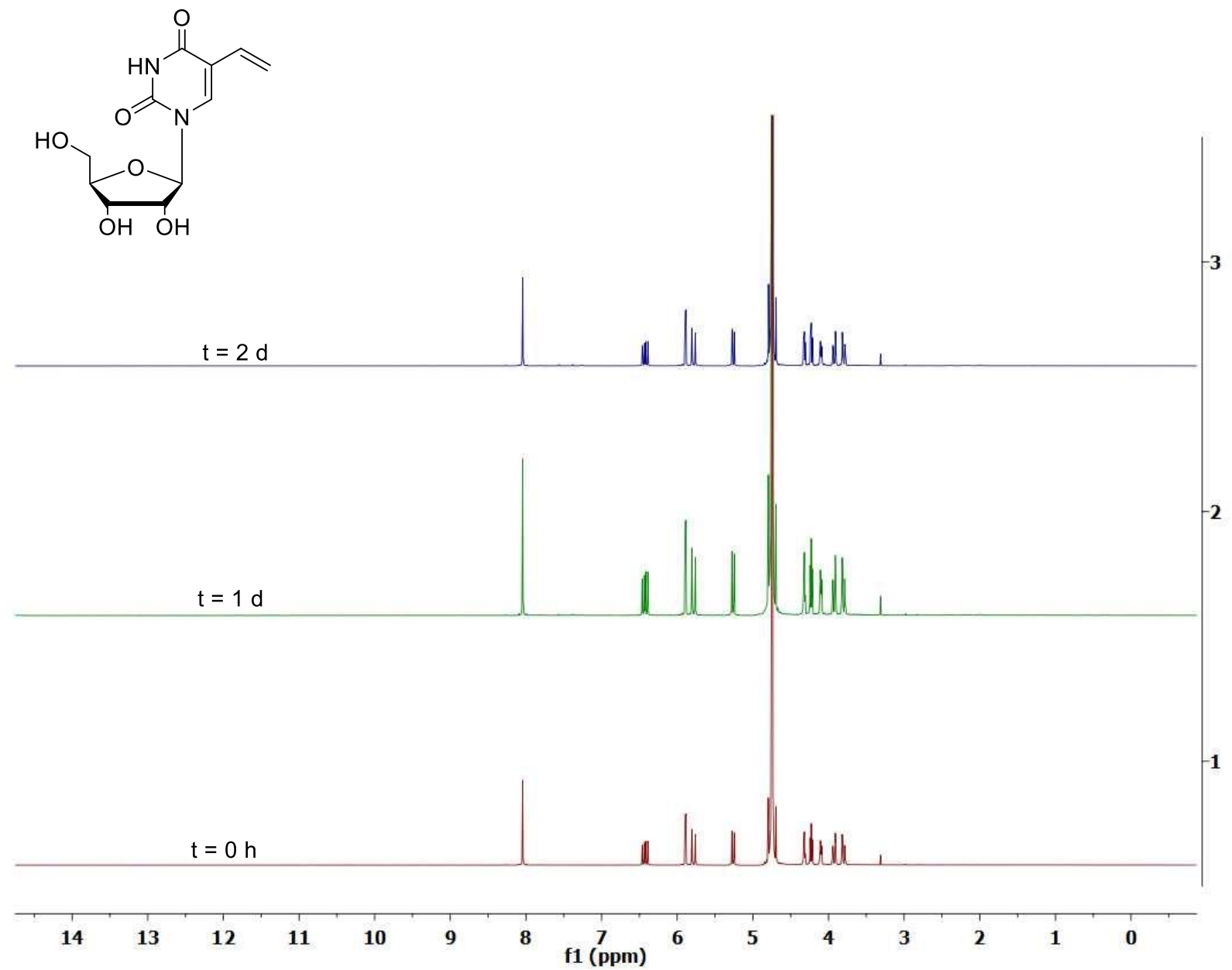

Figure S12. Aqueous stability profile of 5-VU observed over 48 hours. No signs of chemical modification were observed. 


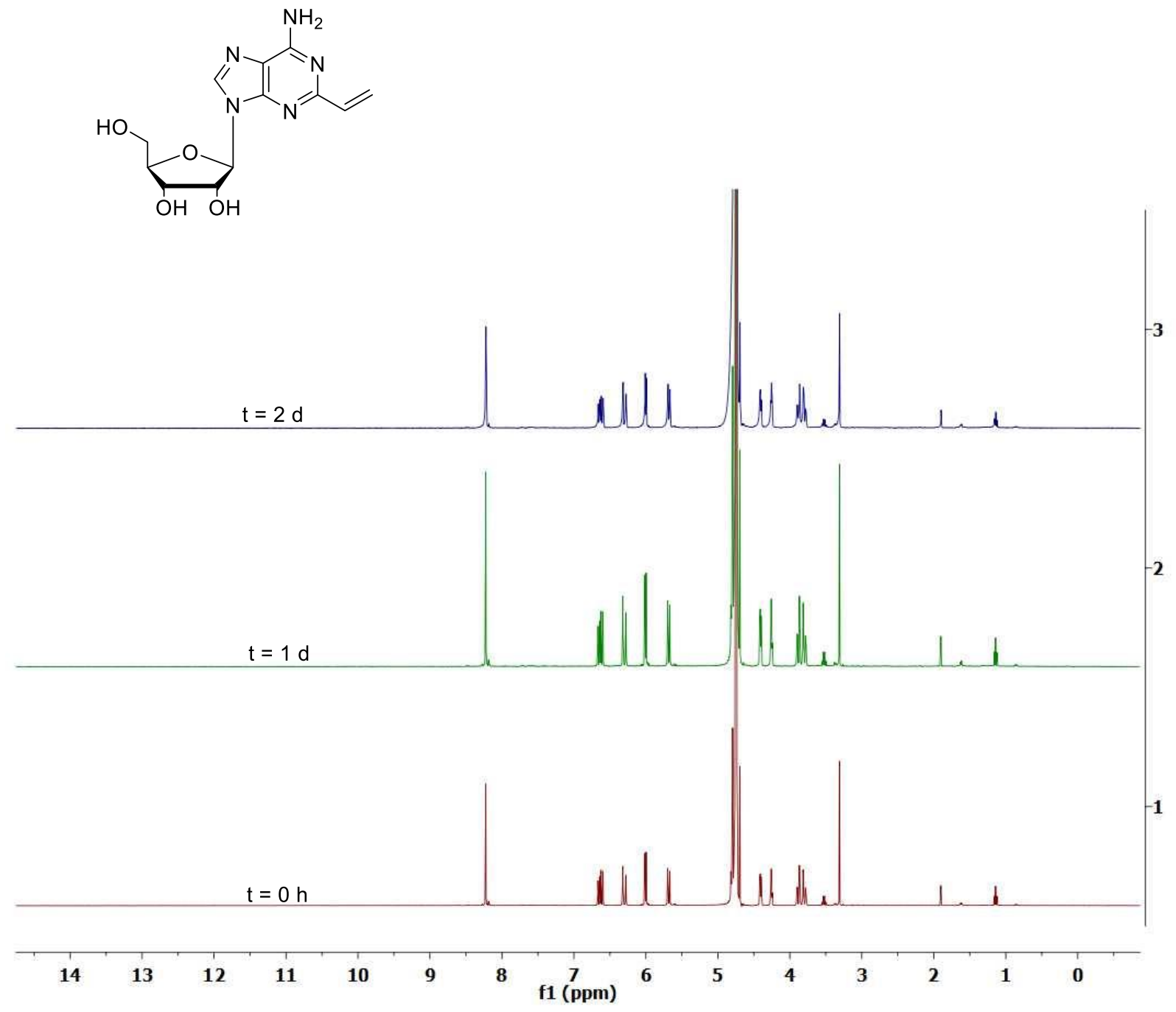

Figure S13. Aqueous stability profile of 2-VA observed over 48 hours. No signs of chemical modification were observed. 


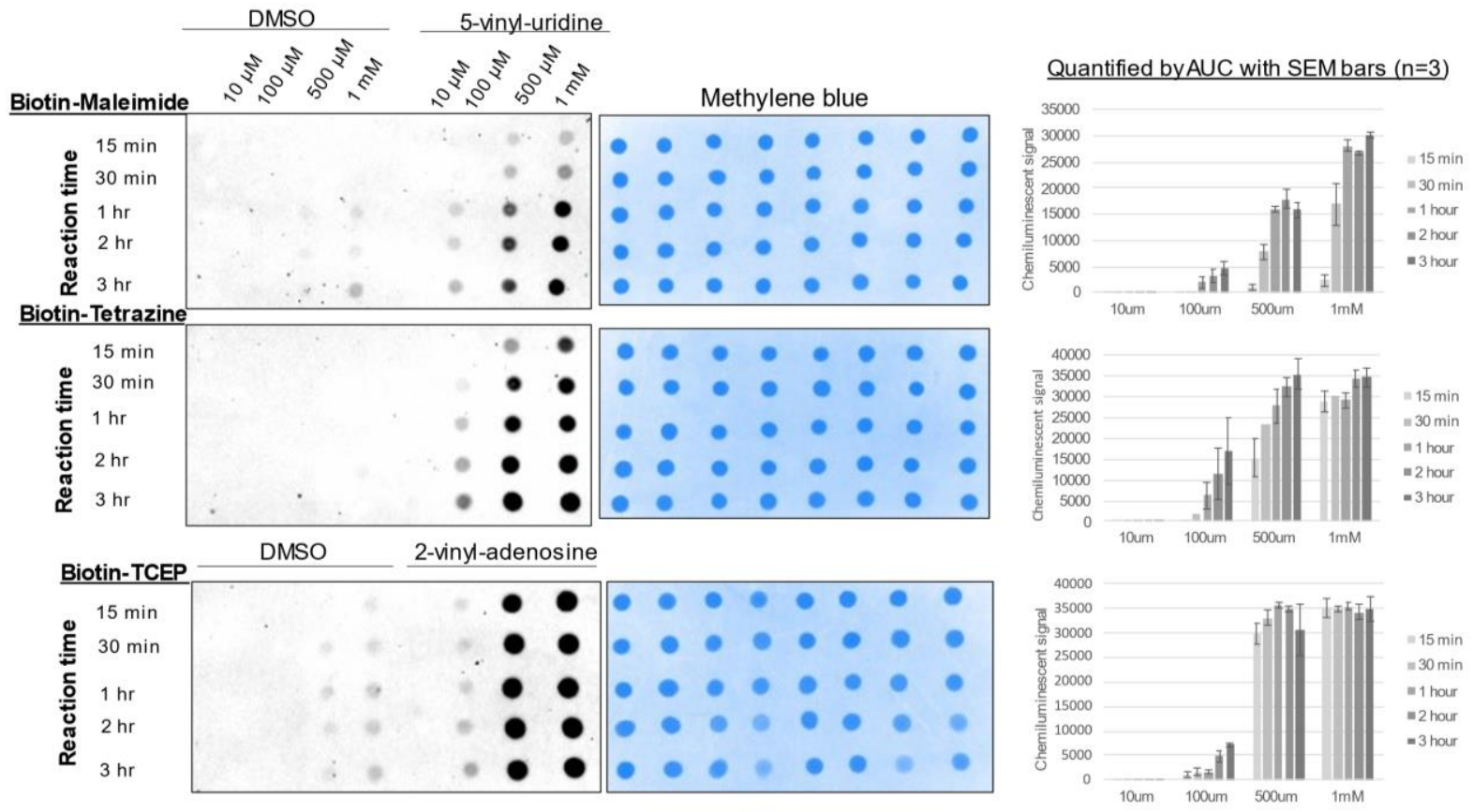

Figure S14. Time and concentration study with biotin-maleimide, biotin-tetrazine and biotinTCEP depicted through dot blot assay and signal quantification with ImageJ software. 


\section{NMR Spectra}

'H NMR (400 MHz, DMSO)
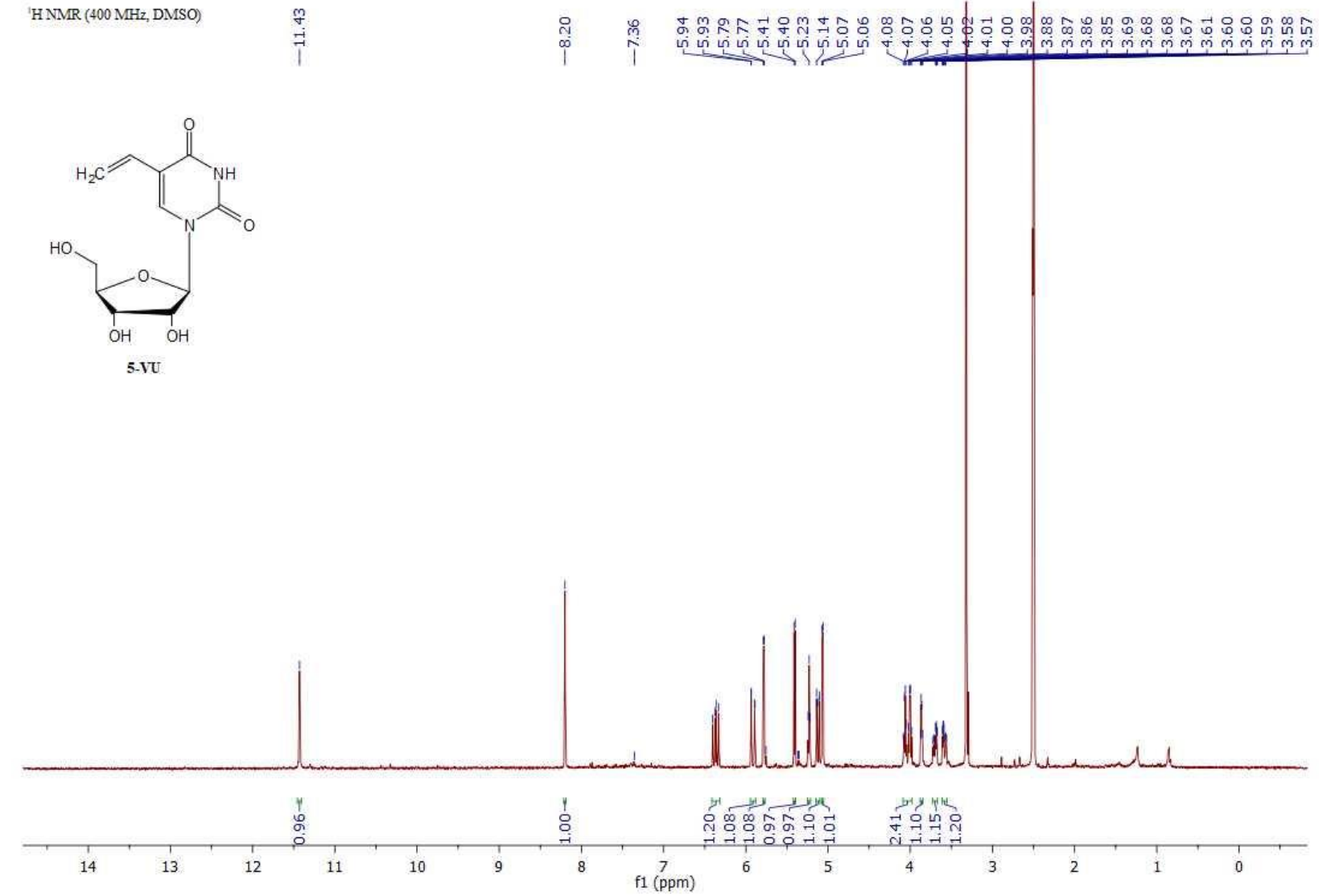

S 
${ }^{13} \mathrm{CNMR}(125 \mathrm{MHz}, \mathrm{DMSO})$

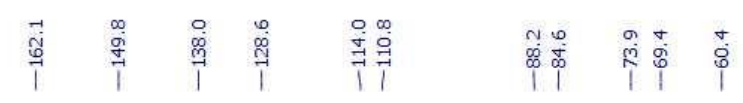
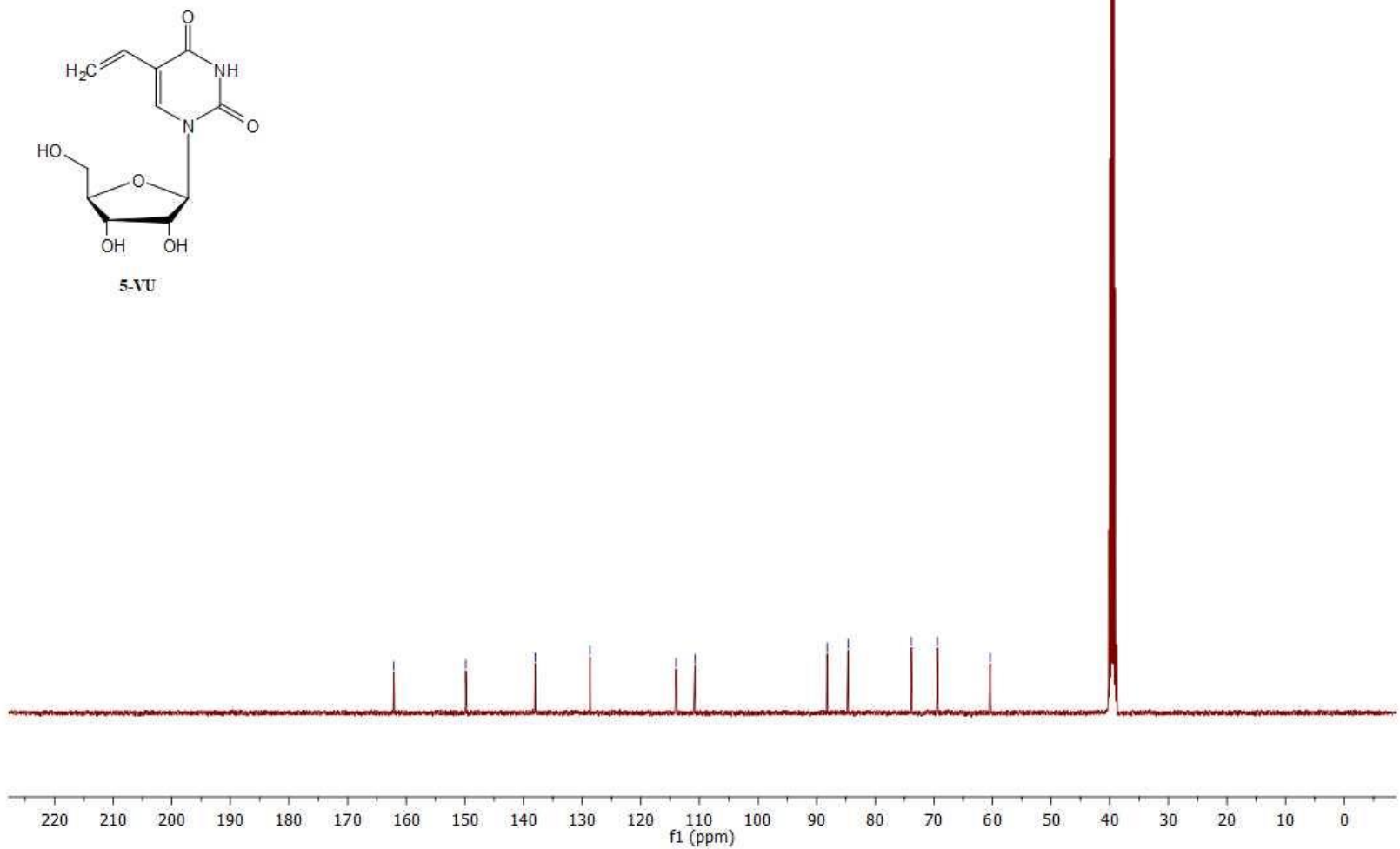
'H NMR (400 MHz, DMSO)

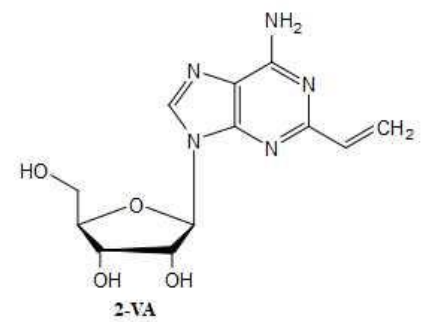

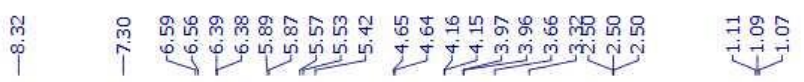

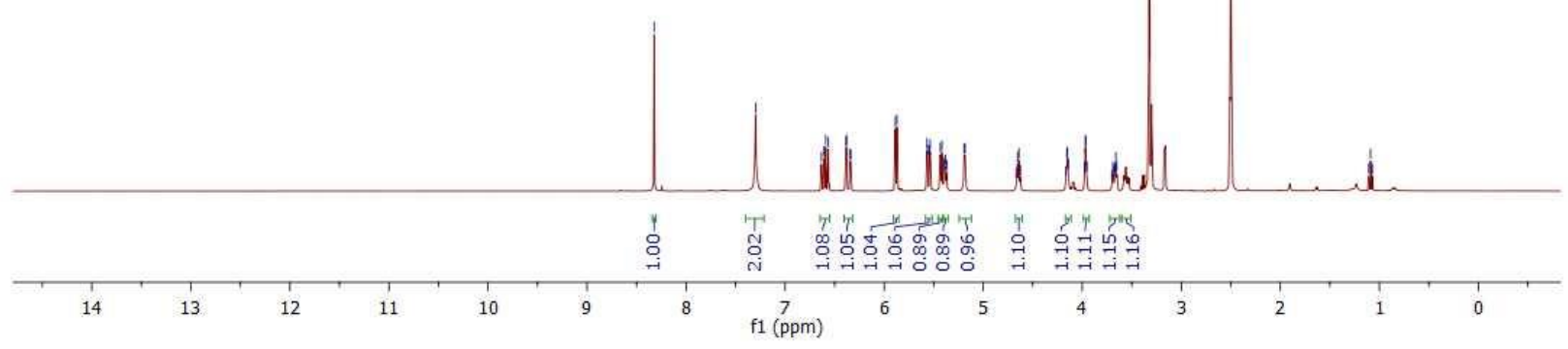


${ }^{13} \mathrm{CNMR}(125 \mathrm{MHz}, \mathrm{DMSO})$.

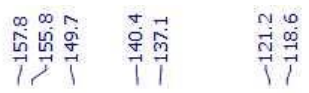

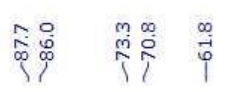<smiles>C=Cc1nc(N)c2ncn(C(O)C(O)CO)c2n1</smiles>

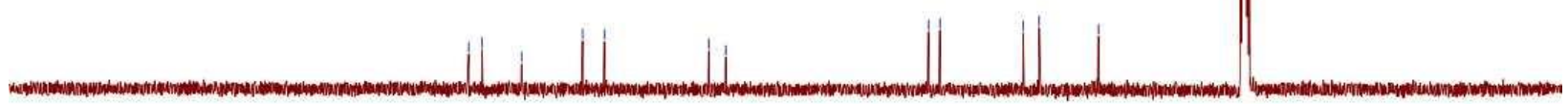

$\begin{array}{lllllllllllllllllllllllll}220 & 210 & 200 & 190 & 180 & 170 & 160 & 150 & 140 & 130 & 120 & \begin{array}{l}110 \\ \mathrm{f} 1(\mathrm{ppm})\end{array} & 100 & 90 & 80 & 70 & 60 & 50 & 40 & 30 & 20 & 10 & 0 & \end{array}$ 


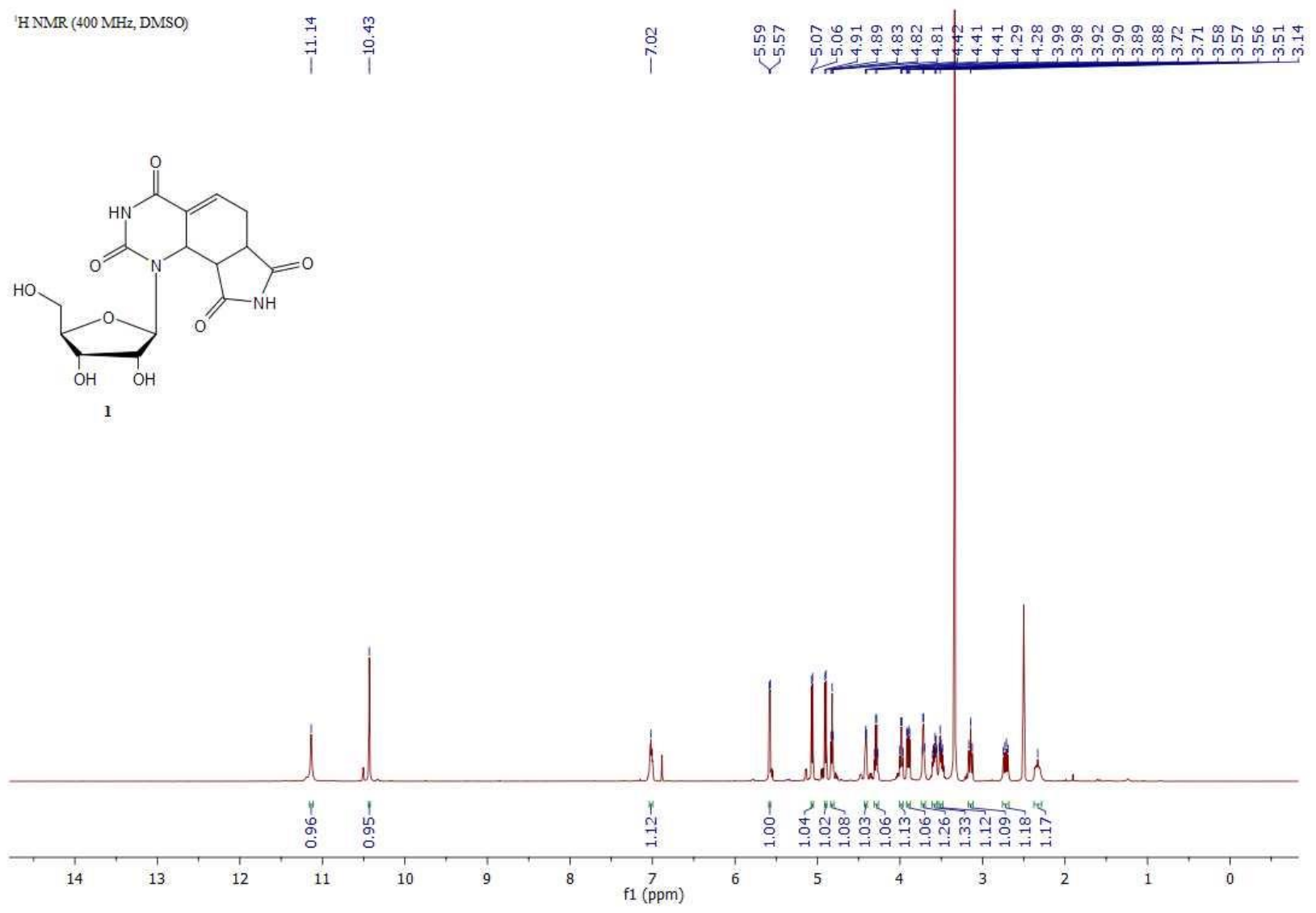




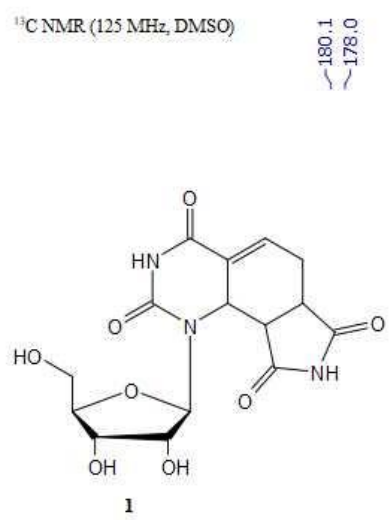

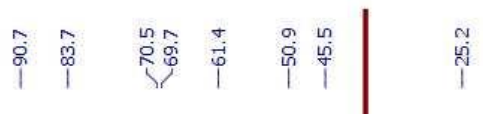

$\begin{array}{lllll}0 & 0 & 0 & 0 \\ 0 & 0 & 0 & 0 \\ 0 & 0 & 0 & 0 \\ 0 & 1 & 1 & 1 & 0\end{array}$
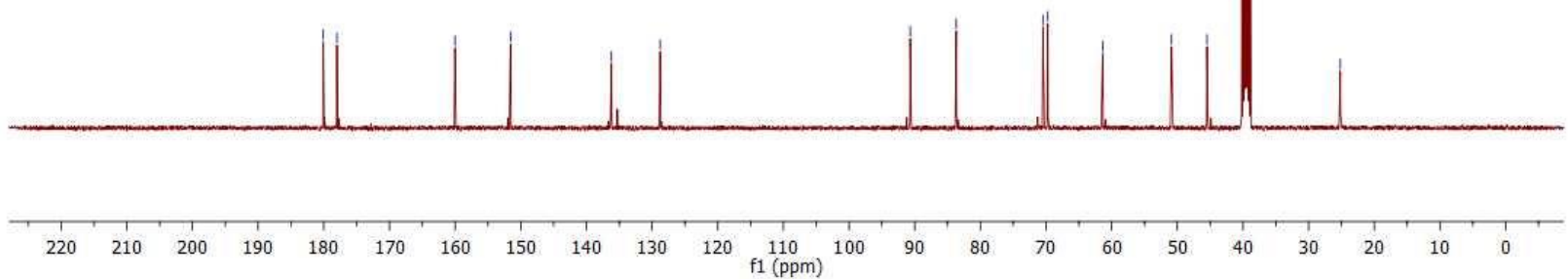


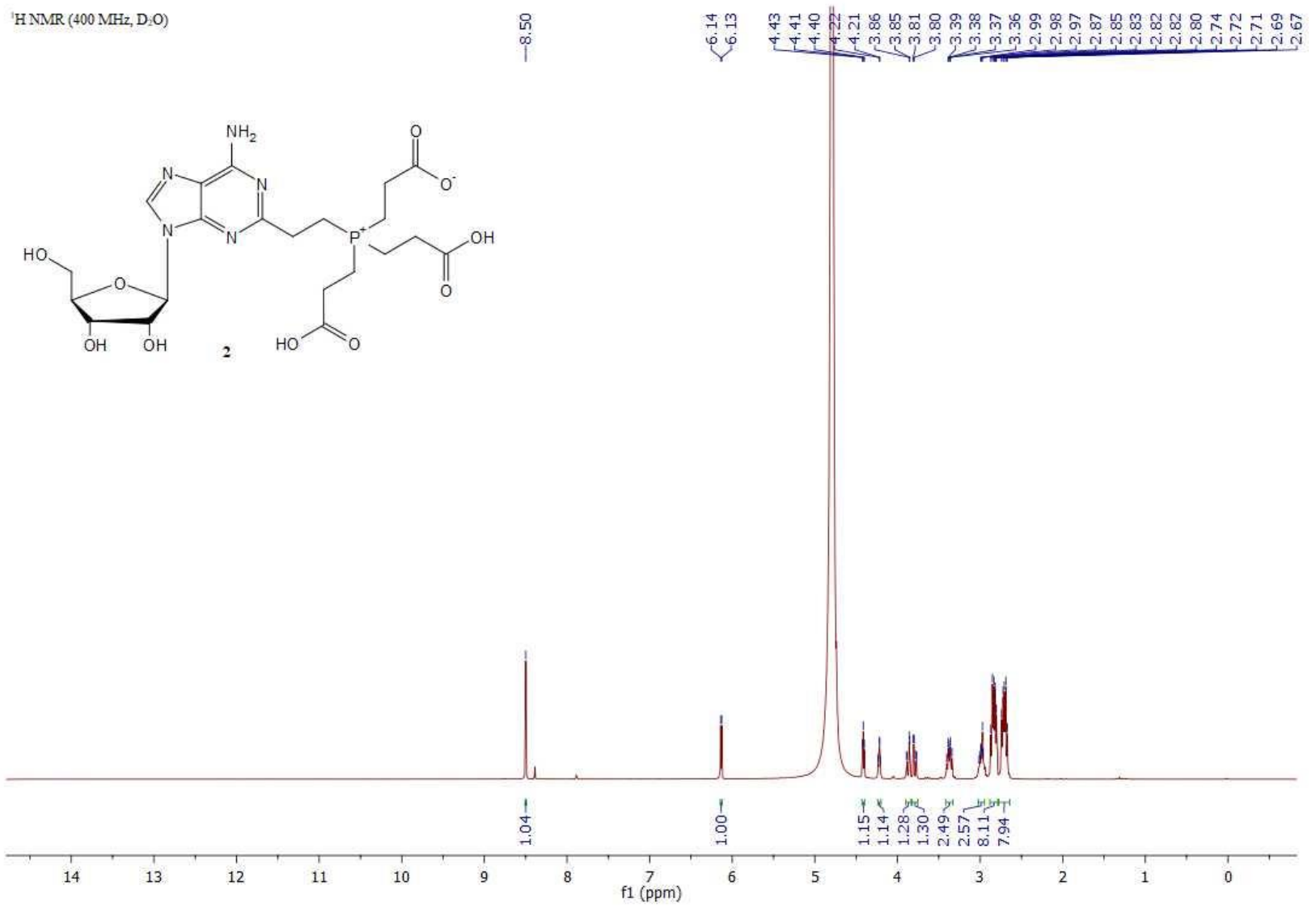



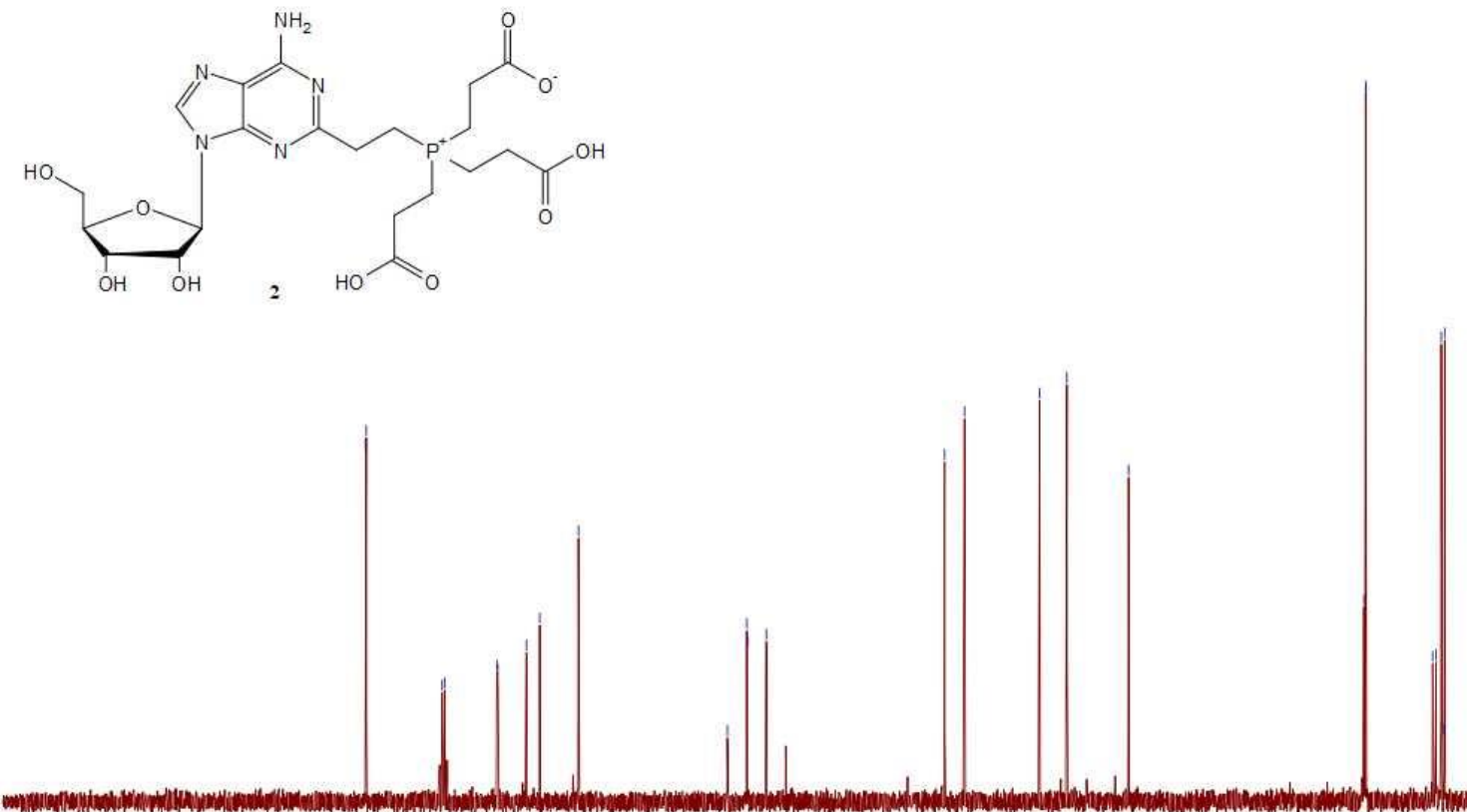

$\begin{array}{llllllllllll}220 & 210 & 200 & 190 & 180 & 170 & 160 & 150 & 140 & 130 & 120 & \begin{array}{l}110 \\ \mathrm{f} 1(\mathrm{ppm})\end{array} \\ 100\end{array}$

90

\section{References}

(1) Grimme, S. Exploration of Chemical Compound, Conformer, and Reaction Space with MetaDynamics Simulations Based on Tight-Binding Quantum Chemical Calculations. J. Chem. Theory Comput. 2019, 15 (5), 2847-2862.

(2) Pracht, P.; Bohle, F.; Grimme, S. Automated Exploration of the Low-Energy Chemical Space with Fast Quantum Chemical Methods. Phys. Chem. Chem. Phys. 2020, 22 (14), 7169-7192.

(3) Spicher, S.; Grimme, S. Robust Atomistic Modeling of Materials, Organometallic, and Biochemical Systems. Angewandte Chemie International Edition 2020, 59 (36), 15665-15673.

(4) Tao, J.; Perdew, J. P.; Staroverov, V. N.; Scuseria, G. E. Climbing the Density Functional Ladder: Nonempirical Meta--Generalized Gradient Approximation Designed for Molecules and Solids. Phys. Rev. Lett. 2003, 91 (14), 146401.

(5) Ahlrichs, R.; Bär, M.; Häser, M.; Horn, H.; Kölmel, C. Electronic Structure Calculations on Workstation Computers: The Program System Turbomole. Chemical Physics Letters 1989, 162 (3), 165-169. 
(6) Grimme, S.; Antony, J.; Ehrlich, S.; Krieg, H. A Consistent and Accurate Ab Initio Parametrization of Density Functional Dispersion Correction (DFT-D) for the 94 Elements H-Pu. J. Chem. Phys. 2010, 132 (15), 154104.

(7) Weigend, F.; Ahlrichs, R. Balanced Basis Sets of Split Valence, Triple Zeta Valence and Quadruple Zeta Valence Quality for H to Rn: Design and Assessment of Accuracy. Phys. Chem. Chem. Phys. 2005, 7 (18), 3297-3305.

(8) Klamt, A.; Schüürmann, G. COSMO: A New Approach to Dielectric Screening in Solvents with Explicit Expressions for the Screening Energy and Its Gradient. J. Chem. Soc., Perkin Trans. 2 1993, No. 5, 799-805.

(9) Balasubramani, S. G.; Chen, G. P.; Coriani, S.; Diedenhofen, M.; Frank, M. S.; Franzke, Y. J.; Furche, F.; Grotjahn, R.; Harding, M. E.; Hättig, C.; Hellweg, A.; Helmich-Paris, B.; Holzer, C.; Huniar, U.; Kaupp, M.; Marefat Khah, A.; Karbalaei Khani, S.; Müller, T.; Mack, F.; Nguyen, B. D.; Parker, S. M.; Perlt, E.; Rappoport, D.; Reiter, K.; Roy, S.; Rückert, M.; Schmitz, G.; Sierka, M.; Tapavicza, E.; Tew, D. P.; van Wüllen, C.; Voora, V. K.; Weigend, F.; Wodyński, A.; Yu, J. M. TURBOMOLE: Modular Program Suite for Ab Initio Quantum-Chemical and Condensed-Matter Simulations. J. Chem. Phys. 2020, 152 (18), 184107.

(10) Dunlap, B. I.; Connolly, J. W. D.; Sabin, J. R. On Some Approximations in Applications of Xa Theory. J. Chem. Phys. 1979, 71 (8), 3396-3402.

(11) Weinhold, F. Natural Bond Orbital Analysis: A Critical Overview of Relationships to Alternative Bonding Perspectives. Journal of Computational Chemistry 2012, 33 (30), 23632379 .

(12) Kubota, M.; Nainar, S.; Parker, S. M.; England, W.; Furche, F.; Spit-ale, R. C. Expanding the Scope of RNA Metabolic Labeling with Vinyl Nucleosides and Inverse Electron-Demand Diels-Alder Chemistry. ACS Chem. Biol. 2019, 14, 1698-1707. 